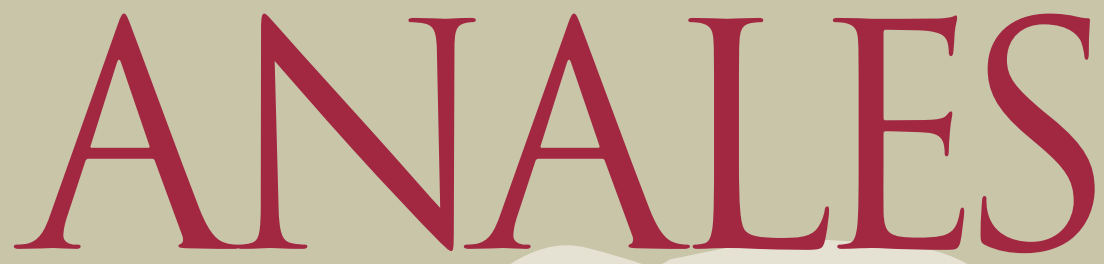

de la Facultad de Derecho

Universidad de La Laguna $35 \quad 2018$ 
Anales de la Facultad de DERECHO 


\section{Anales de la Facultad de DERECHO}

Universidad de La Laguna

DIRECTORA

María Victoria Sansón Rodríguez (ULL)

SUBDIRECTOR

Francisco Lorenzo Hernández González (ULL)

\section{SECRETARIO DE LA REVISTA}

Juan Antonio García García (ULL)

\section{CONSEJO DE REDACCIÓN}

Marcel Bonnet Escuela (ULL), Etelvina de las Casas León (ULL),

Francisco F. Clavijo Hernández (ULL), Ulises Hernández Plasencia (ULL),

Tomás López-Fragoso Álvarez (ULL), Ruth Martinón Quintero (ULL),

Margarita I. Ramos Quintana (ULL), María Elena Sánchez Jordán (ULL).

\section{CONSEJO ASESOR}

Andrea Bonomi (Université de Lausanne, Suiza), Martín Diego Farrell (Universidad de Buenos Aires, Argentina), Antonio Fernández de Buján (Universidad Autónoma de Madrid), Cesare Maioli (Università di Bologna, Italia), María Elvira Méndez Pineda (University of Iceland, Islandia), Manuel Carlos Palomeque López (Universidad de Salamanca), María Ángeles Parra Lucán (Universidad de Zaragoza), Johann-Christian Pielow (RuhrUniversität Bochum, Alemania), Carlos M. ${ }^{a}$ Romeo Casabona (Universidad del País Vasco), María del Carmen Sevilla González (Universidad de La Laguna), Esteban Sola Reche

(Universidad de La Laguna), Rolando Tamayo Salmarán (Universidad Nacional Autónoma de México), Francisco José Villar Rojas (Universidad de La Laguna), Stefan Vogenauer (University of Oxford, Reino Unido).

\section{EDITA}

Servicio de Publicaciones de la Universidad de La Laguna Campus Central. 38200 La Laguna. Santa Cruz de Tenerife Tel.: 34922319198

\section{DISEÑO EDITORIAL}

Jaime H. Vera

Javier Torres/Luis C. Espinosa

\section{MAQUETACIÓN Y PREIMPRESIÓN}

Servicio de Publicaciones

DOI: https://doi.org/10.25145/j.anfade.2018.35

ISSN: 0075-773X (edición impresa) / ISSN: e-2530-8319 (edición digital)

Depósito Legal: TF 734/81

Prohibida la reproducción total o parcial de esta obra sin permiso del editor. 


\section{Anales de la Facultad de DERECHO 35}


ANALES de la Facultad de Derecho de la Universidad de La Laguna. -La Laguna: Universidad, Servicio de Publicaciones, 1991-

Anual

Es continuación de: Anales de la Universidad de La Laguna. Facultad de Derecho.

ISSN 0075-773X

1. Derecho-Publicaciones periódicas I. Universidad de La Laguna. Facultad de Derecho. 34(05)

La correspondencia relativa a la revista debe dirigirse a:

Anales de la Facultad de Derecho

Servicio de Publicaciones

Universidad de La Laguna

Campus Central

38200 La Laguna (Tenerife, España) 


\section{SUMARIO / CONTENTS}

\section{Artículos / Articles}

El Tribunal de Justicia de la Unión Europea y los problemas de legitimidad del proceso de integración / The Court of Justice of the European Union and the legitimacy problems of the integration process

Ruth Martinón Quintero.

La nulidad diferida de las leyes en caso de omisión de informes autonómicos preceptivos / Law's deferred nullity in case of omission of mandatory autonomic reports

Miquel Pons Portella.

On the trade-off between the right of a disabled person to live in an accessible environment and the obligation to protect immovable monuments in polish law / El derecho de una persona con discapacidad a vivir en un entorno de forma funcional y la obligación de proteger los monumentos inmuebles en la legislación polaca 

ARTÍCULOS / ARTICLES 



\title{
EL TRIBUNAL DE JUSTICIA DE LA UNIÓN EUROPEA \\ Y LOS PROBLEMAS DE LEGITIMIDAD \\ DEL PROCESO DE INTEGRACIÓN
}

\author{
Ruth Martinón Quintero \\ Universidad de La Laguna
}

\section{RESUMEN}

Este trabajo trata de mostrar cómo el Tribunal de Justicia de la Unión Europea, debido a su relevancia en el proceso de integración a través de su activismo jurisdiccional, puede afectar no solo a su legitimidad sino a la de la propia Unión Europea. Para ello mostramos el papel que el Tribunal parece haber jugado en el proceso de retirada del Reino Unido de la Unión Europea, en la evolución de algunos aspectos de la institución de la ciudadanía europea y en la plena incorporación de los derechos humanos al Derecho de la Unión.

Palabras Clave: Unión Europea, legitimidad, Tribunal de Justicia de la Unión Europea.

\section{THE COURT OF JUSTICE OF THE EUROPEAN UNION AND THE LEGITIMACY PROBLEMS OF THE INTEGRATION PROCESS}

\begin{abstract}
This paper tries to show how the Court of Justice of the European Union, due to its relevance in the integration process through its judicial activism, can affect its own legitimacy and also European Union's. For that purpose we will see the role the Court seems to have played in British withdrawal from the European Union, in the evolution on some aspects of the European citizenship and in the full incorporation of human rights into European Union law.
\end{abstract}

Keywords: European Union, legitimacy, Court of Justice of the European Union. 
«La legitimidad es la exigencia de justicia que debe cumplir el titular del poder político para contar con el reconocimiento y la obediencia de quienes están sujetos a él $»^{1}$. Los problemas de desafección de los ciudadanos de los Estados miembros respecto a la Unión Europea (en adelante, UE) han cobrado un nuevo protagonismo en la opinión pública tras la victoria de la opción de retirada del Reino Unido en su referéndum del 23 de junio de 2016, aunque no han dejado de estar presentes en todas las propuestas políticas que en diferentes Estados rechazan el proyecto de la Unión. Tradicionalmente, los problemas de legitimidad del proceso de integración europeo y sus instituciones han estado referidos a déficits democráticos, principalmente vinculados a la falta de poder del Parlamento. Con independencia de la paulatina pérdida de fuerza de este argumento en la medida en que el Parlamento Europeo ha ido siendo equiparado al Consejo en el proceso legislativo, es importante seńalar otros elementos que pueden ser utilizados para generar o incrementar esa desafección ciudadana. Del mismo modo que ha habido respuestas jurídicas a este tipo de problemas sociopolíticos (es paradigmática la creación del concepto de ciudadanía europea), también las realidades jurídicas afectan a los problemas de legitimidad que afrontan las instituciones. En esta ocasión vamos a referirnos al papel que pueda jugar en este ámbito la labor del Tribunal de Justicia de la Unión Europea (en adelante, TJUE).

Comenzaremos por recordar el papel del TJUE para destacar su importancia en el proceso de integración europea y la presencia que el activismo judicial tiene en su labor. A continuación nos centraremos en algunos problemas jurídicos concretos en los que el Tribunal ha tenido un papel más o menos protagonista y que consideramos que pueden haber incidido o acabar incidiendo en la legitimidad de la UE.

\section{EL TRIBUNAL DE JUSTICIA DE LA UNIÓN EUROPEA}

Desde la creación de las Comunidades Europeas existe el Tribunal de Justicia como encarnación del poder judicial en estas organizaciones internacionales. Es una de las instituciones que menos cambios ha experimentado a lo largo de estos años, salvo por la necesidad de adaptarse al incremento del número de los Estados miembros y al aumento de asuntos de los que ha de conocer, lo que ha desembocado en la existencia de instancias adicionales ${ }^{2}$.

La misión fundamental del TJUE es garantizar el respeto del Derecho en la interpretación y aplicación de los Tratados, es decir, de las normas fundamentales de la UE. Sin embargo, la función jurisdiccional ordinaria referida al Derecho de la UE corresponde a los jueces y tribunales de los Estados miembros. Es decir,

1 Pérez Luño, A.E.; Soriano Días, R.L.; y Gómez Torres, C.J., Diccionario jurídico. Filosofía y Teoría del Derecho e Informática jurídica, Comares, Granada, 2004.

${ }^{2}$ Regulado en el artículo 19 del TUE, la sección 5. a del Título I de la Parte Sexta del TFUE, y su propio Estatuto, contenido en el Protocolo número 3 anejo a los Tratados. 
del mismo modo que las normas europeas se aplican de manera eminentemente descentralizada por parte de las administraciones de los Estados, también el control jurisdiccional corresponde a los poderes judiciales de estos. Los Estados han de establecer las vías de recurso necesarias para garantizar la tutela judicial efectiva en los ámbitos cubiertos por el Derecho de la Unión.

Ante el TJUE pueden plantear recursos los Estados miembros y las instituciones, y las personas físicas y jurídicas en determinados casos. Se trata de garantizar que tanto los Estados como las instituciones cumplan con la legalidad jurídico-europea. Junto a ello, los órganos jurisdiccionales de los Estados miembros pueden $^{3}$ plantear una cuestión prejudicial sobre la interpretación del Derecho de la UE o sobre la validez de los actos adoptados por las instituciones, de modo que la respuesta del TJUE les sirva para resolver el caso que están conociendo. Es un instrumento muy útil de cara a lograr una interpretación homogénea del Derecho de la UE en todo el territorio de los Estados miembros.

Por todo ello, a lo largo de todos estos años de progresiva integración en Europa, el papel del Tribunal de Justicia ha sido fundamental. Es la institución que ha ido perfilando los principios básicos del ordenamiento jurídico que nace con las Comunidades Europeas, y los principios que habrían de regir la relación de este ordenamiento con los ordenamientos de los Estados miembros ${ }^{4}$. Es decir, sus decisiones e interpretaciones han sido claves para que la integración evolucionase del modo en el que lo ha hecho. Esa relevancia, ese poder, es lo que permite que el Tribunal pueda jugar un papel destacado en la legitimidad de la UE.

Una de las razones por las que el papel ejercido por el TJUE ha supuesto avanzar en la integración (más que en frenarla o ralentizarla) ha sido por su utilización frecuente de la teoría de los poderes implícitos. Las competencias con las que cuentan las instituciones europeas son aquellas que los Estados han atribuido a la organización internacional y a esas instituciones en particular a través de los tratados. Sin embargo, en la práctica, se puede producir una ampliación competencial respecto a lo estipulado en sentido estricto en el Derecho originario. En primer lugar, el actual artículo 352 del Tratado de Funcionamiento de la Unión Europea (en adelante, TFUE) establece que

cuando se considere necesaria una acción de la Unión en el ámbito de las políticas definidas en los Tratados para alcanzar uno de los objetivos fijados por éstos, sin que se hayan previsto en ellos los poderes de actuación necesarios a tal efecto, el

3 Aunque están obligados a ello cuando se trata de un asunto pendiente ante un tribunal nacional cuyas decisiones no son susceptibles de recurso ulterior (artículo 267 TFUE).

${ }^{4}$ De manera simplificada, el TJUE ha caracterizado al ordenamiento jurídico de las Comunidades Europeas antes, de la UE ahora, como un ordenamiento jurídico sui generis (distinto tanto del internacional como del nacional de los Estados), autónomo y beneficiado por los principios de primacía (respecto a los derechos nacionales) y eficacia directa (sin necesidad de actos jurídicos de traslación de muchas de sus normas, que son directamente aplicables por las administraciones nacionales y alegadas en juicio por los enjuiciables). 
Consejo adoptará las disposiciones adecuadas por unanimidad, a propuesta de la Comisión y previa aprobación del Parlamento Europeo.

Junto a ello, el TJUE ha entendido que la existencia de un determinado poder conlleva la de cualquier otro razonablemente necesario para el ejercicio de aquel. En este caso se trataría, más que de establecer una nueva competencia (lo que permitiría el art. 352 TFUE), de ampliar una ya existente ${ }^{5}$.

De un modo u otro esto ha permitido entender que las competencias internas en determinada materia también otorgaban implícitamente competencias externas (de acuerdos con terceros) respecto a esas mismas materias; y permitió desarrollar las políticas de consumidores y medio ambiente, la política regional, la política de investigación y desarrollo tecnológico... antes de que estuvieran recogidas en los tratados, ligadas a la existencia del mercado interior y la necesidad de un «desarrollo armonioso de las actividades económicas [...], una expansión continua y equilibrada ${ }^{6}$.

Puesto que en última instancia es el TJUE el que dictamina si hay una vulneración de los Tratados en el uso de esta técnica jurídica, ha sido objeto de las críticas de quienes han considerado (Estados, tribunales nacionales, länder alemanas, políticos euroescépticos, la misma doctrina ${ }^{7}$ ) su uso abusivo y, por tanto, ilegítimo. En cualquier caso, se trata de actos calificables de activismo judicial y, por tanto, sujetos a una gran subjetividad en cuanto a su valoración.

\section{EL ACTIVISMO JUDICIAL}

La noción de activismo judicial parte siempre, aunque mayoritariamente de manera implícita, de la concepción de la división de poderes y del Estado de Derecho en la que el poder judicial se concibe como un poder sometido al ordenamiento jurídico que ha de limitarse a resolver los litigios atendiendo a lo dispuesto en el mismo. Por tanto, el activismo judicial supondría ir más allá de la mera elección e interpretación de la norma aplicable a cada caso, para suponer una suerte de creación del Derecho por parte de los jueces (making law), y trascendiendo la resolución jurídica del caso concreto.

La traslación de este esquema a la Comunidad internacional exige que los Estados se sometan a las decisiones de los tribunales a quienes confieren su jurisdicción y las cortes internacionales sometan su actividad al derecho producido por los

5 Alonso García, R., Las sentencias básicas del Tribunal de Justicia de la Unión Europea. Estudio y jurisprudencia, Civitas-Thomson Reuters, Pamplona, 2014, pp. 25-26.

${ }_{6}$ Artículo 2 del Tratado Constitutivo de la Comunidad Económica Europea, firmado en Roma el 25 de marzo de 1957, en su redacción original.

7 Es paradigmático el libro de Rasmussen, Hjalte, On law and policy in the European Court of Justice, Martinus Nijhoff, Dordrecht/Boston/Lancaster, 1986. Le respondió CappelletTi, M., «Is The European Court of Justice 'running wild'?», European Law Review, 2015 (3), pp. 311-322 (el original se publicó en el vol. 12, 1, de 1987 de la misma revista). 
propios Estados, en este caso los Tratados que son el Derecho originario de la UE. Lo cierto es que ningún Derecho es lo suficientemente completo y preciso para no dejar margen al poder judicial, al menos en los llamados casos difíciles, en los que la resolución no es sencilla con el Derecho positivo existente ${ }^{8}$.

En cualquier caso, contextualizar se vuelve imprescindible: en cada cultura jurídica se fijan unos límites a la función judicial. El activismo supondría traspasar dichos límites, pero no puede fijarse en términos estrictos respecto al mayor o menor sometimiento a la norma, o la mayor o menor creatividad jurisprudencial, porque el ordenamiento no fija en sí mismo unos límites precisos, y debido a que la actividad judicial es también Derecho'.

Así, aunque en el Derecho internacional en general ${ }^{10}$ y en el Derecho de la UE en particular la jurisprudencia no tiene formalmente capacidad para crear Derecho, en la práctica los tribunales internacionales, y en especial el TJUE, se erigen como voces autorizadas de los principios y normas no escritas, y acaban traspasando la frecuentemente difusa línea que separa la interpretación de la creación del Derecho.

De este modo la apreciación del margen de libertad de los jueces de manera que acabe siendo etiquetado como activismo judicial es una cuestión de grado y depende en gran medida de los intereses y valores de quien está realizando la evaluación, principalmente porque casi siempre es un término que se usa con afán acusatorio, no elogioso y ni siquiera descriptivo. Por ello, y porque toda decisión judicial precisamente por serlo puede ser concebida como una solución legalmente válida,

${ }^{8}$ Así lo encontramos en posiciones por otra parte dispares: HART, H.L. El concepto de Derecho, Abeledo-Perrot, Buenos Aires, 1961, p. 26; y Dworkin, R., Los derechos en serio, Planeta-Agostini, Barcelona, 1977, p. 147. Reflexionando sobre ello, respecto no solo a la existencia sino tambiéna la importancia del making law de los tribunales internacionales en el desarrollo del Derecho internacional, vid. Von Bogdandy, A. y Venzke, «In Whose Name? An Investigation of International Court's Public Authority and Its Democratic Justification», The European Journal of International Law, vo. 23, n. ${ }^{\circ} 1,2012$, pp. 7-41, p. 12.

9 Acogemos aquí una definición amplia de Derecho en el sentido de Alejandro Nieto, para quien el Derecho es el conjunto de los fenómenos reales que se identifican como sus referentes: «En primer lugar, las normas jurídicas [...] junto a las adicciones de los principios generales (de creación estatal, jurisprudencial o doctrinal) y doctrina (tanto jurisprudencial como profesoral); todas ellas vertebradas en el bloque teórico del ordenamiento jurídico. En segundo lugar, los actos jurídicos singulares y concretos, sean de procedencia administrativa judicial o privada y que forman parte del Derecho aunque no sean ordenamiento jurídico. Y en tercer lugar, los hechos jurídicos [...] que son atraídos a la esfera del Derecho por la fuerza de la gravedad de sus consecuencias jurídicas» (NiETo, A., Crítica de la razón jurídica, Trotta, Madrid, 2007, p. 17).

${ }^{10} \mathrm{El}$ artículo 38.1.d) del Estatuto de la Corte Internacional de Justicia (ETIJ), marco de referencia del sistema de fuentes del Derecho internacional, recoge las decisiones judiciales solo como un medio auxiliar para la determinación de las reglas de derecho. Sin embargo, la importancia de la jurisprudencia internacional es evidente y no ha dejado de crecer. Su relevancia tiene origen en las propias características del ordenamiento jurídico internacional, en el que los jueces no solo han tenido que interpretar la norma, sino también con mucha frecuencia han de constatar y precisar la existencia de normas consuetudinarias o de los mismos principios generales y los principios estructurales del Derecho internacional (Boyle, A. y Chinkin, C., The Making of International Law, Oxford University Press, Oxford, 2007, p. 263 y ss.) 
el activismo judicial depende en cada caso de las convenciones sociales sobre cuál es el papel adecuado del poder judicial, de modo que el activismo se produce cuando se traspasan los límites de dicho pape ${ }^{11}$. Por todo ello no es difícil detectar cómo se etiquetan como activismo judicial las decisiones que no gustan, y se acepta como jurisprudencia legítima aquella que es acorde con la propia concepción.

Es un lugar común considerar que uno de los tribunales internacionales cuya actividad puede calificarse más frecuentemente de activismo judicial es el TJUE. Ese activismo, surgido desde muy temprano, fue generalmente apoyado por el papel que esa jurisprudencia europea suponía en la consolidación e incluso el avance en el proceso de integración a través del ejercicio de la función de interpretación de un Derecho con frecuencia abierto y contradictorio. Sin embargo, tampoco han faltado las críticas de quienes observaron extralimitaciones en el Tribunal. Por lo que hemos expuesto, no es fácil precisar cuándo se produce esa extralimitación, pero sí parece claro que en la medida en que consideremos que esa extralimitación se produce comienzan las amenazas a la legitimidad del Tribunal ${ }^{12}$.

A continuación vamos a tratar tres cuestiones recientes en las que el TJUE ha jugado un papel directo o indirecto y que pueden servir para explicar el impacto que este puede ocasionar en la legitimidad de la Unión. En primer lugar, trataremos el rol que parece haber jugado el Tribunal en el proceso que dio lugar a la activación por el Reino Unido del artículo 50 del Tratado de la Unión Europea. En segundo lugar, presentaremos algunos problemas experimentados por la institución de la ciudadanía de la UE los últimos años: el acceso a los servicios sociales del Estado de acogida por parte de ciudadanos de otros Estados miembros en condiciones desventajosas, y la interacción entre la libre prestación de servicios y la libre circulación de trabajadores, y su incidencia en el principio de igualdad y no discriminación entre nacionales de los Estados miembros. Por último, abordaremos brevemente la negativa del TJUE a la adhesión de la UE al Convenio Europeo de Derechos Humanos y Libertades Fundamentales (en adelante, CEDH) del Consejo de Europa.

\section{EL PROCESO DE RETIRADA DEL REINO UNIDO DE LA UNIÓN EUROPEA}

El 10 de noviembre de 2015, el primer ministro del Reino Unido, David Cameron, envió una carta a Donald Tusk, presidente del Consejo Europeo, proponiendo un nuevo acuerdo para el Reino Unido en una Unión Europea reformada. Con ello intentaba convencer al electorado de su país de que votaran no a la salida

11 Zarbiyev, F., "Judicial Activism in International Law -A Conceptual Framework for Analysis», Journal of International Dispute Settlement, núm. 3, (2), 2012, pp. 1-32, p. 5.

12 Cappelletti, M., "Is the European Court of Justice 'running wild'?», European Law Review, vol. 40 (3), 2015, pp. 311-322, p. 312. El artículo original se publicó en la misma revista en 1987, vol. 12 (1), pp. 3-17. También Zarbiyev, F., op. cit., pp. 9-10. 
de la UE en un referéndum que él mismo se había comprometido a celebrar ${ }^{13}$. La carta abordó cuatro ámbitos de reformas: gobernanza económica, competitividad, soberanía e inmigración. En cuanto a la soberanía, se propuso poner fin a la obligación británica de trabajar hacia una unión más estrecha tal y como establece el Preámbulo del Tratado de la Unión Europea. De esta forma se trataba de hacer desaparecer un objetivo que permite al TJUE legitimar muchas decisiones de la UE. De hecho, en las Conclusiones con las que el Consejo Europeo respondió a la carta en febrero de 2016 se recogió, en la parte dedicada al tema de la soberanía, que

las referencias hechas en los Tratados y sus preámbulos al proceso creador de una unión cada vez más estrecha entre los pueblos de Europa no constituyen una base jurídica para ampliar el ámbito de aplicación de cualquier disposición de los Tratados o del Derecho derivado de la UE. Tampoco deberían servir para apoyar una interpretación extensiva de las competencias de la Unión o de los poderes de sus instituciones con arreglo a lo establecido en los Tratados.

Los recelos respecto al papel del TJUE en el Reino Unido son antiguos: «Los efectos concretos del dinamismo del Tribunal de Justica de las Comunidades Europeas fueron pronto sentidos dentro del Reino Unido $»^{14}$, donde la eficacia directa del Derecho de la UE supuso un desafío a la soberanía parlamentaria tal y como se concebía tradicionalmente. Si bien es cierto que la judicatura británica ha sido progresivamente más adepta a reconciliar dicha primacía con esa concepción de la soberanía ${ }^{15}$, particular y propia de un país sin Constitución escrita.

En cualquier caso, este no fue un tema estrella de la campańa electoral del referéndum. Sin embargo, sí parece ser que ha sido importante en el proceso de negociación que está en marcha en la medida en que la primera ministra, Theresa May, colocó como una de las líneas rojas de su posición el que el Reino Unido no vuelva a estar bajo la jurisdicción del TJUE ${ }^{16}$. Lo cierto es que en el primer acuerdo firmado entre la UE y el Reino Unido respecto a la primera fase de la negociación se ha establecido que los conceptos del Derecho de la UE referidos a los derechos de los ciudadanos (adquiridos antes de la retirada) han de ser interpretados dentro del respeto de la jurisprudencia de la Corte, de modo que

${ }_{13}$ Que finalmente se celebró el 23 de junio de 2016 y supuso la victoria de la salida de la Unión Europea, lo que llevó a la activación del artículo 50 TUE a través de la carta del 29 de marzo de 2017 que la primera ministra británica envió al presidente del Consejo Europeo.

${ }_{14}$ Hannesson, O.I. y Bangsund, K., «Life on the Edge: EFTA and the EEA as a Future for the UK in Europe», European Public Law, vol. 22 (1), 2016, pp. 69-96, p. 72.

${ }^{15}$ Hannesson, O.I. y Bangsund, K., op. cit., p. 74.

16 «Brexit and the courts», The Economist, edición impresa, 26 de agosto de 2017. En el mismo sentido, Theresa May, al pedir un acuerdo de seguridad con la UE precisó que tal acuerdo no estaría sujeto al TJUE porque «esa fue precisamente una de las razones por las que muchos británicos quisieron salir de la UE» («May pide un nuevo acuerdo de seguridad con la UE en un ańo», $E l$ País, edición impresa, 18 de febrero de 2018, p. 6). 
los tribunales británicos «han de tener debidamente en cuenta» las decisiones del TJUE posteriores a la retirada ${ }^{17}$.

Con independencia de cuál sea la posición del Reino Unido tras consumarse su retirada de la UE, y la consiguiente relación con el TJUE, este proceso muestra cómo el TJUE puede constituirse en arma arrojadiza para quienes quieren cuestionar el proceso de integración europea. Esto no significa que el papel del TJUE haya sido determinante, ni mucho menos, en este proceso de abandono de la UE por parte del Reino Unido. De hecho, este país siempre ha tenido una relación a mbivalente y distante con el proceso de integración europea que se ha reflejado con constantes diferenciaciones recogidas en múltiples protocolos a los Tratados: para mantener su moneda ${ }^{18}$, no participar en el acervo Schengen y realizar controles fronterizos de personas ${ }^{19}$, decidir si participa o no en las medidas del espacio de libertad, seguridad y justicia ${ }^{20}$, o la excepción a los derechos sociolaborales recogidos en el Título IV de la Carta de Derechos Fundamentales de la UE ${ }^{21}$.

\section{LA CIUDADANÍA EUROPEA}

El concepto jurídico de ciudadanía europea aparece en el Tratado de Maastricht $^{22}$ en 1992, como un haz de derechos más allá de los que se les habían otorgado a los europeos desde los Tratados constitutivos como actores económicos (empresarios, trabajadores, usuarios, consumidores...). El origen de esta perspectiva más cívico-política que habría de completar la económica se encuentra en el desapego percibido en los ciudadanos europeos respecto al proceso de integración y tiene como finalidad servir al ciudadano, que pasa a convertirse en objetivo explícito de dicho proceso. Tiene su culminación en el Título V de la Carta de los Derechos Funda-

17 Joint report from the negotiators of the European Union and the United Kingdom Government on progress during phase 1 of negotiations under Article 50 TEU on the United Kingdom's orderly withdrawal from the European Union, publicado en la web del Grupo del Trabajo Artículo 50 el 8 de diciembre de 2017, párrafos 9, 38. Véase también párrafo 39. Además, el TJUE permanece competente (y sus sentencias vinculantes) para los procedimientos judiciales del Reino Unido registrados a la fecha de la retirada (párrafo 93).

${ }^{18}$ Protocolo $n .^{\circ} 15$ anexo al TUE, al TFUE y al Tratado Constitutivo de la Comunidad Europea de la Energía Atómica sobre determinadas disposiciones relativas al Reino Unido de Gran Bretaña e Irlanda del Norte.

19 Protocolo n. ${ }^{\circ} 20$ anexo al TUE, al TFUE y al Tratado Constitutivo de la Comunidad Europea de la Energía Atómica sobre la aplicación de determinados aspectos del artículo 26 del Tratado de Funcionamiento de la Unión Europea al Reino Unido y a Irlanda.

${ }^{20}$ Protocolo ${ }^{\circ} 21$ anexo al TUE, al TFUE y al Tratado Constitutivo de la Comunidad Europea de la Energía Atómica sobre la posición del Reino Unido y de Irlanda respecto del espacio de libertad, seguridad y justicia.

${ }^{21}$ Protocolo $n .^{\circ} 30$ anexo al TUE, al TFUE y al Tratado Constitutivo de la Comunidad Europea de la Energía Atómica, sobre la aplicación de la Carta de los Derechos Fundamentales de la UE a Polonia y al Reino Unido.

22 Artículo G, apartado C del Tratado de la Unión Europea de 7 de febrero de 1992. 
mentales de la UE, jurídicamente vinculante desde la entrada en vigor del Tratado de Lisboa ${ }^{23}$.

Consideramos que este es también un ámbito en el que el TJUE puede haber incidido en su legitimidad y en la de la propia UE en la medida en que en los últimos años su jurisprudencia no ha sido clara en el respaldo a la institución de la ciudadanía europea frente a las libertades económicas en algunos ámbitos. Uno de ellos ha sido el referido a los derechos de protección social de quienes han hecho uso de la libertad de circulación y residencia.

Desde los Tratados constitutivos existió el derecho de libre circulación y residencia pero se trataba de un derecho vinculado al ejercicio de una actividad económica. Es decir, derecho de libre circulación y residencia para acceder a un empleo asalariado, a un empleo por cuenta propia, a prestar o recibir un servicio, a establecerse profesionalmente o a abrir un negocio, eliminando la discriminación por razón de nacionalidad (entre ciudadanos de los Estados miembros) y con un régimen de protección social limitado a establecer principios de coordinación entre los derechos nacionales de seguridad social ${ }^{24}$.

A partir de la inclusión del derecho a la libre circulación y residencia como parte de la ciudadanía europea ${ }^{25}$, este pasa a ser un derecho de todo ciudadano de la UE y se impulsa o amplía el principio de no discriminación por razón de nacionalidad en los ámbitos de aplicación de los Tratados ${ }^{26}$. Sin embargo, se trata de un derecho sujeto a las limitaciones y condiciones previstas en los Tratados y en las disposiciones adoptadas para su aplicación. Así, la Directiva 2004/38/CE ${ }^{27}$ establece que por períodos inferiores a tres meses el derecho es irrestricto pero sin derecho a reclamar beneficios sociales; para períodos superiores a tres meses se exige actividad económica o disponer de recursos suficientes y un seguro médico para no resultar

${ }^{23}$ Artículo 6.1 TUE: La Unión reconoce los derechos, libertades y principios enunciados en la Carta de los Derechos Fundamentales de la Unión Europea de 7 de diciembre de 2000, tal como fue adaptada el 12 de diciembre de 2007 en Estrasburgo, la cual tendrá el mismo valor jurídico que los Tratados.

${ }^{24}$ Capítulos 1, 2 y 3 del Título III del Tratado Constitutivo de la Comunidad Económica Europea, firmado en Roma el 25 de marzo de 1957, en su versión original.

${ }_{25}$ Artículo 8A del artículo G, apartado C del Tratado de la Unión Europea de 7 de febrero de 1992. Actualmente, artículos 20.2 a) y 21 TFUE.

26 Si bien es verdad que en 1990 el Consejo aprobó tres directivas mediante las que extendió el derecho de libre circulación y residencia a los inactivos laborales (rentistas, jubilados, pensionistas, estudiantes) y sus familias, siempre que dispusiesen de recursos suficientes y seguro de enfermedad para que no se convirtieran, durante su estancia, en una carga para el Estado de acogida.

27 Directiva 2004/38/CE del Parlamento Europeo y del Consejo, de 29 de abril de 2004, relativa al derecho de los ciudadanos de la Unión y de los miembros de sus familias a circular y residir libremente en el territorio de los Estados miembros por la que se modifica el Reglamento (CEE) n. ${ }^{\circ} 1612 / 68$ y se derogan las Directivas 64/221/CEE, 68/360/CEE, 72/194/CEE, 73/148/CEE, 75/34/CEE, 75/35/CEE, 90/364/CEE, 90/365/CEE y 93/96/CEE. 
una carga para el Estado de acogida ${ }^{28}$. En cualquier caso siempre con la posibilidad de que los Estados establezcan excepciones relativas al orden público, seguridad y salud públicas ${ }^{29}$.

Lo cierto es que la propia regulación tanto en los Tratados como en el Derecho derivado y el cúmulo de conceptos jurídicos indeterminados como «carga excesiva» ha permitido que el TJUE haya tenido un margen bastante amplio para determinar las consecuencias finales de muchas de estas normas.

En general, la mayor parte de los problemas se refieren a los no económicamente activos que sin contar con suficientes recursos para la subsistencia demandan prestaciones sociales en un Estado al que se han desplazado y llevan más de tres meses (períodos inferiores no dan derecho a prestaciones de ningún tipo ${ }^{30}$ ). En un primer momento el TJUE aceptó el derecho a las mismas si estas tenían como finalidad la integración en el mercado de trabajo (acercando por tanto el concepto de demandante o buscador de empleo al de sujeto económicamente activo ${ }^{31}$; y en el caso de que eso no se produjese, cabía mostrar el vínculo real con el Estado de $\operatorname{acogida}^{32}$. La evolución de la jurisprudencia ha adoptado una senda claramente restrictiva, desembocando en la negación directa del acceso a las prestaciones sociales a ciudadanos económicamente no activos que no busquen empleo de forma efectiva (denominado "turismo social» $\mathrm{o}$ "turismo de pobreza») sin atender al vínculo real con el Estado de acogida y tampoco el de la proporcionalidad de la decisión adoptada ${ }^{33}$.

Un paso más en el desarrollo de esa jurisprudencia restrictiva lo constituye la sentencia del TJUE de 14 de junio de $2016^{34}$. En este caso, no se trata de la negación de prestaciones de asistencia social, sino de prestaciones propias y no controvertidas de seguridad social respecto de personas con ciudadanía europea, pero económicamente no activas y que no cumplen los requisitos de residencia de la normativa británica. La Comisión denunció al Reino Unido por incumplimiento del Regla-

${ }^{28}$ Directiva 2004/38/CE, de 29 de abril de 2004, en particular artículos 6 y 7. El artículo 16 regula el derecho de residencia permanente a partir de un período continuado de residencia legal de cinco ańos en el Estado miembro de acogida.

${ }^{29}$ Artículo 45.3 TFUE y capítulo vi Directiva 2004/38/CE, de 29 de abril de 2004.

30 Recientemente confirmado por TJUE, sentencia de 25 de febrero de 2016, García Nieto, C-299/14, párrafo 45: «Dado que los Estados miembros no pueden exigir que los ciudadanos de la Unión posean medios de subsistencia suficientes y una cobertura médica personal cuando realizan una estancia de tres meses de duración como máximo en sus respectivos territorios, es legítimo no obligar a dichos Estados miembros a hacerse cargo de esos ciudadanos durante tal período».

31 TJCE, sentencia de 4 de junio de 2009, Vatsouras y Koupatantze, C-22/08 y C-23/08.

32 TJUE, sentencia de 19 de septiembre de 2013, Brey, C-140/12.

33 TJUE, sentencia de 11 de noviembre de 2014, Dano, C-333/13; TJUE, sentencia de 15 de noviembre de 2015, Alimanovic, C-67/14; TJUE, sentencia de 25 de febrero de 2016, García Nieto, C-299/14.

34 TJUE, sentencia de 14 de junio de 2016, Comisión vs. Reino Unido, C-308/14, en especial párrafos 75 y 80 . 
mento $^{35}$ de coordinación de los sistemas de seguridad social cuyo objetivo es, precisamente, garantizar a las personas que se desplazan dentro de la UE los derechos que hayan adquirido o estén adquiriendo. Para el TJUE, el ordenamiento comunitario no se opone a que el reconocimiento de prestaciones sociales a ciudadanos de la Unión que no ejerzan actividades económicas se condicione, por el Estado competente, a que los mismos cumplan el requisito de tener derecho de residencia legal en el Estado de acogida. El hecho de que esa residencia legal ${ }^{36}$ de acuerdo a la legislación británica exija una comprobación de la residencia habitual en su territorio que no se exige a los nacionales británicos tampoco fue considerado por el TJUE contrario al principio de igualdad de trato tal y como alegó la Comisión, si se trata de una medida proporcional a la necesidad de salvaguardar las finanzas del Estado miembro de acogida.

Quienes han denunciado esta deriva restrictiva de la jurisprudencia del TJUE en torno al derecho al acceso a prestaciones sociales asistenciales de los ciudadanos comunitarios económicamente inactivos exigen a las instituciones comunitarias afrontar esta situación en el ámbito normativo de la UE y que se proceda a modificar el Derecho derivado, para no solo cubrir la vertiente económica de la libertad de circulación y residencia, por ejemplo atendiendo al vínculo real y efectivo como criterio de solidaridad social entre los Estados miembros, o incluyendo al «demandante de empleo» como sujeto económicamente activo. En definitiva, que se precise la extensión del derecho de acceso a las prestaciones sociales de subsistencia para quienes en esa situación se desplazan a territorio de otros Estados miembros distintos al de su nacionalidad. De lo contrario, se estaría consolidando un estatuto de ciudadano de la UE próximo al de migrante extranjero extracomunitario, vaciando de contenido la institución de ciudadanía en el ámbito de la libre circulación y residencia ${ }^{37}$.

Dentro de esta misma fricción entre los derechos de ciudadanía y las libertades económicas encontramos el problema de los derechos de los trabajadores desplazados en virtud de la libre prestación de servicios, el cual surge de la interacción entre dicha libertad y la libre circulación de trabajadores con sus correspondientes derechos.

En 1990, el TJUE abrió las puertas a una nueva fórmula de movilidad laboral en el ámbito comunitario con su sentencia en el caso Rush Portuguesa ${ }^{38}$, cuando reconoció a los prestadores de servicios el derecho a desplazarse con su personal,

35 Reglamento (CE) N. ${ }^{\circ} 883 / 2004$ del Parlamento Europeo y del Consejo de 29 de abril de 2004 sobre la coordinación de los sistemas de seguridad social.

${ }^{36}$ En el Reglamento (CE) N. ${ }^{\circ} 883 / 2004$, por el contrario, se entiende por residencia «el lugar en el que una persona reside habitualmente» (artículo 1.j).

37 Para un análisis más detallado del mismo, vid. SÁnChez-Urán Azaña, M.Y., «Derecho de residencia y protección social de subsistencia», en García Murcia, J. (dir.), Libertades de circulación y derechos de protección social en la Unión Europea, Juruá, Vila Nova de Gaia, 2016, pp. 339-373. fos 12 y 18 .

38 TJCE, sentencia de 27 de marzo de 1990, Rush Portuguesa, C-1 13/89, en especial párra- 
garantizando simultáneamente a los Estados la posibilidad de aplicar su legislación laboral a tales trabajadores. Con ello, se lograba un punto de equilibrio entre la libertad económica de los prestadores de servicios y la protección de los mercados laborales locales frente a la introducción de mano de obra desplazada, en todos los sectores económicos y niveles de cualificación. Sin embargo, como veremos, la jurisprudencia posterior generó una fractura en ese sistema de contrapesos, desarrollando una concepción muy amplia de libertad de empresa en su dimensión organizativa, al impedir la mejora de las condiciones de trabajo de los trabajadores desplazados, cuando estas «obstaculizan» el comercio de servicios.

La Directiva 96/71/CE ${ }^{39}$ estableció en su artículo 3 que los Estados miembros velarían por que, cualquiera que sea la legislación aplicable a la relación laboral, las empresas que trasladasen trabajadores a su territorio haciendo uso de la libertad de prestación de servicios garantizasen a los trabajadores desplazados en su territorio las condiciones de trabajo y empleo relativas a las materias siguientes: las que en el Estado miembro donde se efectúe el trabajo, estuviesen establecidas por disposiciones legales, reglamentarias o administrativas; $y$ las que estuvieran establecidas por convenios colectivos o laudos arbitrales declarados de aplicación general y que se refiriesen a los períodos máximos de trabajo, así como los períodos mínimos de descanso; la duración mínima de las vacaciones anuales retribuidas; las cuantías de salario mínimo, incluidas las incrementadas por las horas extraordinarias; la presente letra no se aplicará a los regímenes complementarios de jubilación profesional; las condiciones de suministro de mano de obra, en particular por parte de agencias de trabajo interino; la salud, la seguridad y la higiene en el trabajo; las medidas de protección aplicables a las condiciones de trabajo y de empleo de las mujeres embarazadas o que hayan dado a luz recientemente, así como de los niños y de los jóvenes; la igualdad de trato entre hombres y mujeres y otras disposiciones en materia de no discriminación.

El objetivo de esta Directiva era «unificar las condiciones de trabajo y empleo de los trabajadores transfronterizos en el marco de las prestaciones de servicios intracomunitarias" para evitar el dumping social ${ }^{40}$. Sin embargo, el TJUE interpretó que esta Directiva tenía la capacidad de prohibir aquello a lo que no obligaba (concretando así en esta área la cláusula de comercio negativa contenida en el artículo 56 del TFUE) configurándola como una norma de mínimos en su proyección comunitaria y como norma de máximos en su proyección estatal. De este modo, la jurisprudencia comunitaria dificultaba la intervención estatal o sindical dirigida a evi-

39 Directiva 96/71/CE del Parlamento Europeo y del Consejo de 16 de diciembre de 1996 sobre el desplazamiento de trabajadores efectuado en el marco de una prestación de servicios.

40 Gil Pérez, M.E., «Repensando el núcleo duro de condiciones de trabajo en el estado de acogida y la protección de los trabajadores desplazados», en Fotinopoulou Basurko, O. (coord.), Presente y futuro del desplazamiento de trabajadores en el marco de la Unión Europea, Atelier, Barcelona, 2017, pp. 173-188, p. 174. 
tar el dumping social ${ }^{41}$. Es decir, los Estados solo pueden extender a los trabajadores desplazados aquellas condiciones de trabajo y empleo distintas a las enumeradas en art. 3.1 de la Directiva 96/71/CE utilizando la noción excepcional de orden público. De modo que habría que extender la prohibición a las medidas nacionales que aun sin tener por finalidad la regulación de los intercambios de servicios entre los Estados miembros puedan tener un efecto real o potencial en el mismo, disuadiendo a prestadores de servicios extranjeros de ejercer tal libertad, obstaculizando la prestación de servicios.

Esta interpretación se vio reforzada por la Directiva 2014/67/UE ${ }^{42}$, que «tiene como finalidad garantizar que se respete un nivel apropiado de protección de los derechos de los trabajadores desplazados para la prestación de servicios transfronteriza, en particular que se cumplan las condiciones de empleo aplicables en el Estado miembro donde se vaya a prestar el servicio, de conformidad con el artículo 3 de la Directiva 96/71/CE, facilitando al mismo tiempo el ejercicio de la libre prestación de servicios a los prestadores de los mismos y promoviendo la competencia leal entre ellos, apoyando así el funcionamiento del mercado interior» (artículo 1.1.). Al no entrar en la interpretación pretoriana de la Directiva 96/71/CE, la Directiva 2014/67/UE consolidó definitivamente la expulsión de los trabajadores desplazados del ámbito de protección de la libre circulación de trabajadores.

Esta jurisprudencia refleja un menosprecio de los derechos de los europeos como trabajadores, pero se aleja aún más del contenido político intrínseco al concepto de ciudadanía, que recordaba el abogado general Jacobs ${ }^{43}$ con estas palabras:

La prohibición de la discriminación por razón de la nacionalidad es asimismo de una gran importancia simbólica, en la medida en que demuestra que la Comunidad no es un mero acuerdo comercial entre los Gobiernos de los Estados miembros, sino una empresa común en la que todos los nacionales de Europa pueden participar como personas. Los nacionales de cada Estado miembro tienen derecho a vivir, trabajar y ejercer actividades económicas en otros Estados miembros en las mismas condiciones que la población nacional. No deben ser simplemente tolerados como extranjeros, sino recibidos favorablemente por las autoridades del Estado de acogida como nacionales comunitarios que tienen derecho, «en el ámbito de aplicación del Tratado", a todos los privilegios y ventajas de que gocen los nacionales del Estado de acogida. Ningún otro aspecto del Derecho de la Unión afecta al individuo más directamente ni hace más por fomentar el sentido de identidad común y destino

${ }^{41}$ Llobera-Vila, M., «Evolución normativa de la regulación comunitaria relativa al desplazamiento de trabajadores", en Fotinopoulou Basurko, O. (coord.), Presente y futuro del desplazamiento de trabajadores en el marco de la Unión Europea, Atelier, Barcelona, 2017, pp. 39-65, p. 64.

${ }^{42}$ Directiva 2014/67/UE del Parlamento Europeo y del Consejo de 15 de mayo de 2014 relativa a la garantía de cumplimiento de la Directiva 96/71/CE, sobre el desplazamiento de trabajadores efectuado en el marco de una prestación de servicios, y por la que se modifica el Reglamento (UE) n. ${ }^{\circ}$ 1024/2012 relativo a la cooperación administrativa a través del Sistema de Información del Mercado Interior («Reglamento IMI»).

${ }_{43}$ Conclusiones del Abogado General EG Jacobs presentadas el 30 de junio de 1993 (asuntos acumulados C-92/92 y C-326/92, Phil Collins), párrafo 11. 
compartido sin el cual la «unión cada vez más estrecha entre los pueblos europeos», proclamada en el preámbulo del Tratado, sería un eslogan vacío.

El artículo 45 del TFUE establece que sin perjuicio de las limitaciones justificadas por razones de orden público, seguridad y salud públicas, la libre circulación de los trabajadores implicará el derecho, entre otros, «de residir en uno de los Estados miembros con objeto de ejercer en él un empleo, de conformidad con las disposiciones legales, reglamentarias y administrativas aplicables al empleo de los trabajadores nacionales». Su respeto habría de impedir que el desplazamiento de trabajadores se utilizase para aprovechar inferiores condiciones laborales en otros Estados miembros. Porque no se trata solo de conseguir un alto grado de integración económica, sino también de la construcción de una ciudadanía europea real.

La inaplicación del art. 45 TFUE que supone la aplicación de la Directiva 96/71/CE (tal como ha sido interpretada por el TJUE) y la Directiva 2014/67/UE imposibilita que la garantía de paridad de trato pueda actuar como desincentivo al dumping social, y coloca el Derecho del Trabajo como obstáculo al comercio intracomunitario (barrera no arancelaria ${ }^{44}$ ).

La denuncia de esta situación ha supuesto varios intentos de reforma de estas directivas. Finalmente, en marzo de 2017, la Comisión presentó una propuesta que ha culminado con la aprobación de la Directiva (UE) $2018 / 957^{45}$, en la que se han introducido modificaciones sobre el principio de igualdad de trato. En particular, se ha limitado el carácter de trabajador desplazado a doce meses ${ }^{46}$, de modo que después de ese tiempo la ley aplicable al contratado de trabajo dejaría de ser la del lugar de origen para ser la del Estado de destino (salvo en materia de celebración y resolución del contrato y regímenes complementarios de jubilación). Además, se ha sustituido la referencia del artículo 3 de la Directiva a las cuantías de salario mínimo por una referencia a la remuneración. En la medida en que esta comprenderá todos los elementos retributivos obligatorios puede interpretarse en el sentido de que los empleados que ejerzan temporalmente en otro Estado miembro deben recibir el mismo salario que los locales si realizan el mismo trabajo para evitar la competencia desleal de empresas que prefieren traer mano de obra extranjera más barata.

Sin embargo, esta nueva directiva no rompe con el sustrato general con el que se ha abordado, con el protagonismo del TJUE, la relación entre la libertad

44 Vid. Llobera-Vila, M, «La directiva 96/71/CE: un instrumento de eliminación de barreras no arancelarias (BNA)», en Fotinopoulou Basurko, O. (coord.), Presente y futuro del desplazamiento de trabajadores en el marco de la Unión Europea, Atelier, Barcelona, 2017, pp. 67-74.

45 Directiva (UE) 2018/957 del Parlamento Europeo y del Consejo de 28 de junio de 2018 que modifica la Directiva 96/71/CE sobre el desplazamiento de trabajadores efectuado en el marco de una prestación de servicios.

46 «Cuando el prestador de servicios presente una notificación motivada, el Estado miembro en que se preste el servicio ampliará el período previsto en el párrafo primero a 18 meses» (nuevo artículo 1 bis de la Directiva 96/71/CE). 
de prestación de servicios y la libertad de circulación de trabajadores, incluso de la misma noción de ciudadanía de la Unión en su expresión de derecho a circular y residir libremente en los territorios de los Estados miembros (art. 21 TFUE). Ello es así en la medida en que el concepto de trabajador utilizado en estas directivas y en la jurisprudencia del TJUE ha objetivado al ciudadano al situarlo como mero elemento de la prestación de servicios. Se desprecia la relación laboral entre un empresario y un trabajador regida por una serie de derechos y deberes, y el trabajador desplazado carece de entidad jurídica propia. Como explica Llobera-Vila ${ }^{47}$ :

La posición jurídica del trabajador queda absorbida por la de su empleador, y confundida en el entramado de medios jurídicos y productivos que permiten al prestador de servicios hacer efectiva su libertad de circulación. [...] En el mercado interior de servicios el trabajo sirve instrumentalmente a la libertad empresarial que [...] se funde con ésta logrando arrastrar los elementos «laborales» a un territorio jurídico en el que quedan sujetos a un juicio de proporcionalidad, que los evalúa a partir de su capacidad restrictiva de dicha libertad empresarial, y en el que [el] trabajo va asumiendo jurídicamente una posición de factor de producción como otro cualquiera. Esta perspectiva legislativa prescinde del trabajador como sujeto primario de regulación, para situar al prestador de servicios, desposeído en gran medida de la condición de empleador, en el centro del razonamiento jurídico.

\section{LOS DERECHOS HUMANOS EN EL TJUE}

Los Tratados fundacionales de las Comunidades Europeas no contemplaron ninguna disposición específica sobre los derechos humanos, los cuales no se mencionan en el Derecho originario hasta el Tratado de la Unión Europea en 1992. Una de las explicaciones que se han dado a la no contemplación de los derechos fundamentales en esos primeros tratados reside en que parecía difícil concebir posibles interferencias entre las regulaciones de carácter eminentemente económico que se establecían y derechos fundamentales principalmente referidos en ese momento a la categoría de los derechos civiles y políticos. También es cierto que el nacimiento en 1949 del Consejo de Europa y la firma en su seno un ańo más tarde del CEDH pareció llevar a «un acuerdo tácito de distribución de papeles entre las dos organizaciones europeas: la una, el Consejo de Europa, elaboraría el más perfecto mecanismo de protección internacional de los derechos humanos conocido hasta la fecha; las otras, esforzándose por crear lazos de solidaridad material entre los pueblos de Europa, tendrían como primera meta el establecimiento de un mercado común ${ }^{48}$.

${ }^{47}$ Llobera-Vila, M., op. cit., p. 64.

48 Pérez Vera, E., «La problemática adhesión d la Unión Europea al Convenio Europeo de Derechos Humanos", en Alcaide Fernández, J. y Petit de Gabriel, E.W. (eds.), España y la Unión Europea en el orden internacional. XXVI Jornadas Ordinarias de la AEPDIRI, Tirant lo Blanch, Valencia, 2017, p. 59. 
Lo cierto es que el propio proceso de integración de las Comunidades Europeas acabó generando colisiones con el respeto a los derechos humanos, lógicamente acrecentadas tras la asunción competencial en el ámbito de la cooperación policial y judicial en materia penal (Tratado de la Unión Europea de 1992); o tras la comunitarización de la materia relativa a visados, asilo, inmigración y la cooperación judicial en material civil (Tratado de Ámsterdam). Ante esta situación, y tras una primera etapa descrita como «inhibicionista ${ }^{49}$, el Tribunal de Justicia ha sido el que ha ido incorporando progresivamente los derechos humanos al Derecho comunitario desde finales de la década de los años sesenta. En concreto, este tribunal ha venido dictaminado el reconocimiento y la obligatoriedad de los derechos fundamentales como principios generales del Derecho sobre la base de un triple fundamento: los derechos fundamentales comprendidos dentro de los principios generales del Derecho de la Unión Europea; la parte dogmática de los textos y las tradiciones constitucionales comunes de los Estados miembros; y los instrumentos jurídico-internacionales de los que son parte los Estados miembros en materia de derechos humanos, en especial, el $\mathrm{CEDH}^{50}$.

De este modo, los tribunales constitucionales de los Estados miembros, que ante la postura «inhibicionista» mostraron reticencias a respetar el principio de primacía en este ámbito ${ }^{51}$, iniciaron una nueva doctrina denominada «de la protección equivalente ${ }^{52}$ de acuerdo a la cual en tanto las Comunidades Europeas garantizasen una protección de los derechos fundamentales equivalente en lo esencial a la de los textos constitucionales, los tribunales constitucionales no ejercerían competencia jurisdiccional en materia de aplicación del Derecho derivado y, por tanto, no lo revisarían en función de los derechos fundamentales recogidos en sus constituciones.

La jurisprudencia incluyente de los derechos humanos en el Derecho de la UE se vio reforzada por declaraciones de las instituciones de la Unión y por las sucesivas modificaciones de los Tratados, pero era una cuestión que necesitaba solventarse de manera definitiva a través de dos vías: una declaración propia de derechos humanos y la adhesión al CEDH, del que siempre han sido parte todos los Estados miembros. La primera vía cobró forma con la Carta de Derechos Fundamentales de la UE aprobada en Niza en el año 2000, si bien no obtuvo carácter vinculante hasta el Tratado de Lisboa al situarla entre el Derecho originario junto a los Tratados (artículo 6.1 TUE).

${ }^{49}$ López Rozas, J.C., «La compleja adhesión de la Unión Europea al Convenio Europeo de Derechos Humanos y las secuelas del Dictamen 2/2013 del Tribunal de Justicia», La Ley Unión Europea, núm. 23, 2014, pp. 40-56, p. 43.

50 TJCE, sentencia del de 14 de mayo de 1974, Nold, Asunto 4/72, párrafos 12 y 13.

51 Martinón, R., «Los derechos humanos en la UE. En especial, el problema de la adhesión de la Unión al CEDH», Revista Europea de Derechos Fundamentales, núm. 28, 2016, pp. 49-71, p. 51.

52 Tribunal Constitucional alemán, sentencia 22 de octubre de 1986, Solange II. 
La otra vía, la adhesión de las Comunidades Europeas al CEDH, se vio frenada por un escueto dictamen ${ }^{53}$ del TJUE de 1996 en el que se afirmaba que un acto de tal magnitud necesitaba estar recogido en los Tratados. Eso es lo que hicieron los Estados con el Tratado de Lisboa al establecer en el artículo 6.2 del Tratado de la Unión Europea que «la Unión se adherirá al Convenio Europeo para la Protección de los Derechos Humanos y de las Libertades Fundamentales. Esta adhesión no modificará las competencias de la Unión que se definen en los Tratados».

Con esta afirmación los Estados respondían al Dictamen 2/1994 dejando atrás la falta de competencia, lo que, unido al reconocimiento formal a la Unión Europea de personalidad jurídica (art. 47 TUE), parecía significar la superación de los obstáculos anteriores para la adhesión, aunque ello debiera hacerse dentro de los márgenes permitidos por el Protocolo 8 Sobre el apartado 2 del artículo 6 del Tratado de la Unión Europea relativo a la adhesión de la Unión al CEDH.

Pese a este explícito mandato de los Estados para que se llevara a cabo la adhesión al CEDH, el TJUE impidió tal adhesión al considerar en su Dictamen 2/2013 que el preacuerdo alcanzado entre el Consejo de Europa y la UE no era acorde al Derecho de la UE. En este caso se trata de una dictamen largo ${ }^{54}$ que observa múltiples obstáculos para cumplir con el artículo 6.2 TUE, si bien casi todos ellos pueden reconducirse a un temor del TJUE a ser enjuiciado por otro tribunal aunque se trate de un tribunal especializado en derechos humanos que ya tiene jurisdicción sobre todos los Estados miembros de la UE, incluso cuando estos actúan de acuerdo al Derecho de la UE. De este modo, el principio de autonomía que proclama el TJUE del ordenamiento comunitario parece convertirse en autarquía $a^{55}$; una autonomía aún mayor que la de los propios Estados soberanos que sí aceptan la función jurisdiccional del Tribunal de Estrasburgo para la mejor salvaguarda de los derechos fundamentales.

Hasta este dictamen la relación entre el TJUE y el Tribunal Europeo de Derecho Humanos (en adelante, TEDH) ha sido muy positiva. El TJUE ha ido incorporando el CEDH y la jurisprudencia del Tribunal de Estrasburgo en su argu-

53 Tras la aprobación del Tratado de la Unión Europea el 7 de febrero de 1992 (y su recién incorporada ciudadanía europea) el Consejo solicitó una opinión consultiva al TJ sobre si era posible (recurriendo al artículo 235 del Tratado de la Comunidad Europea, actual 352 TFUE) entender que la protección de los derechos humanos constituía una competencia implícita, transversal a toda política comunitaria, suficiente para fundamentar dicha adhesión. El Dictamen 2/94 del Tribunal de Justicia mostró su posición de manera breve y concisa acerca de la imposibilidad de la misma por la inexistencia de base jurídica para dicha adhesión. Es decir, por entender que la Comunidad Europea carecía de competencia para firmar tratados internacionales en materia de derechos humanos, de modo que la adhesión requeriría la modificación de los Tratados.

54 Para un análisis más detallado del mismo, vid. Martinón Quintero, R., «Los derechos humanos en la UE. En especial, el problema de la adhesión de la Unión al CEDH», Revista Europea de Derechos Fundamentales, núm. 28, 2016, pp. 49-71.

${ }^{55}$ Martín y Pérez de Nanclares, J., «El TJUE pierde el rumbo en el Dictamen 2/13: ¿Merece todavía la pena la adhesión de la UE al CEDH?», Revista de Derecho Comunitario Europeo, núm. 52, 2015, pp. 825-869, p. 844. 
mentación jurídica, si bien lo ha hecho a través del filtro de los principios generales; como un elemento de interpretación de indudable valor hermenéutico pero sin eficacia jurídica directa. Es decir, aunque el Tribunal cita con frecuencia la jurisprudencia del Tribunal de Estrasburgo, evita considerarse expresa e irremediablemente constreñido por la misma, para erigirse así en el máximo intérprete de los derechos fundamentales, incluidos los contenidos en el CEDH, en el ámbito de la Unión Europea. La aplicación indirecta del contenido del CEDH como principios generales, de los que es guardián e intérprete supremo el propio Tribunal de Justicia, garantiza la autonomía y la primacía del Derecho de la UE. De modo que el Tribunal de Luxemburgo se mantiene como máximo intérprete del CEDH en el contexto comunitario, incluso cuando asume la interpretación jurisprudencial del Tribunal de Estrasburgo ${ }^{56}$.

Por su parte, el TEDH ha desarrollado un control mediato o indirecto del Derecho de la Unión Europea a través de la ejecución que los Estados hacen del mismo a partir de dos principios: la imposibilidad de dejar a los ciudadanos desprotegidos en sus derechos respecto al Derecho comunitario, por un lado; y la necesidad de desarrollar una cooperación activa con otra organización internacional que muestra una historia de respeto al sistema de Estrasburgo ${ }^{57}$. De este modo, se considera que los Estados miembros son responsables del respeto a las obligaciones del Convenio aun en áreas donde el ejercicio de la competencia se ha transferido a la organización supranacional, e incluso donde tienen un margen reducidísimo de aplicación y apreciación como en el caso de los reglamentos. Es decir, los Estados parte en el Convenio no están exentos de responsabilidad por los ámbitos de competencia atribuidos a la Unión o que son consecuencia de aquellos. Sería difícil aceptar que se pueda reducir la eficacia del $\mathrm{CEDH}$ a las personas en su jurisdicción sobre la base de la transferencia de ciertos poderes a la Unión Europea.

Uno de los problemas de estos casos en los que el TEDH ha controlado de forma mediata el respeto al CEDH en la aplicación y ejecución del Derecho de la Unión por parte de sus Estados miembros ha sido la imposibilidad de que la Unión pueda concurrir como parte litigante para defender su posición. Al mismo tiempo, ante la inexistencia de una legitimación pasiva de la Unión en el sistema de control del CEDH, los individuos que han entendido que sus derechos eran vulnerados por alguna decisión o actuación de las instituciones de la Unión Europea han

56 Hay quienes han llegado a hablar de una «convencionalización« del Derecho de la Unión, en el sentido de su progresiva integración en el ámbito -sustantivo y procedimental-del Convenio Europeo. Vid. López Guerra, L., "Derechos e integración europea», en Ugartemendía Eceizabarrena, J.I. y Jáuregui Bereciartu, G. (coords.), Derecho Constitucional Europeo. Actas del VIII Congreso de la Asociación de Constitucionalistas de España, Tirant lo Blanch, Valencia, 2011, pp. 33-34.

57 En la sentencia del caso Bosphorus se muestra una genuina combinación de estos principios con una jurisprudencia deferente (TEDH, sentencia de 30 de junio de 2005, Bosphorus Airways c. Irlanda, n. ${ }^{\circ} 45036 / 98$, en especial, párrafos 147 y 159-165). 
interpuesto una demanda contra todos sus Estados miembros, habiendo finalmente casos que han sido admitidos a trámite por el $\mathrm{TEDH}^{58}$.

La importancia de todo ello es enorme, ya que supone un control del Derecho de la Unión Europea casi equiparable al que existiría si esta se adhiriese al CEDH, lo que algunos vieron como una motivación a «la adhesión de la Unión Europea al $\mathrm{CEDH}$, en la medida en que la solución retenida por el TEDH produce, en cierta medida, consecuencias similares a la adhesión ${ }^{59}$. Solo si el acto nacional en el origen de la violación no es más que una simple y pura transcripción del Derecho Comunitario, el Estado no será responsable respecto del Convenio, a condición de que el Derecho Comunitario ofrezca una protección equivalente de los derechos fundamentales $^{60}$ (equiparable a la doctrina Solange del Tribunal Constitucional alemán).

No es difícil suponer que el TEDH ponga fin a esa presunción de protección equivalente, y en general que la buena relación entre ambos tribunales no pueda continuar, si bien parece inevitable seguir intentando la adhesión como mandato jurídico expreso que es. Lo cierto es que, con independencia de cuestiones de técnica jurídica, este Dictamen del TJUE incide directamente en su legitimidad, y esta vez de manera bastante independiente del resto de las instituciones de la UE porque es una posición en gran medida solitaria, que se desentiende del problema clave de la protección de los derechos humanos, que queda ajena a su argumentación. Con ello se pierde, al menos de momento, la oportunidad de conectar adecuadamente la labor de ambos tribunales y se pone en riesgo la aproximación progresiva de ambas jurisprudencias de las últimas décadas.

\section{REFLEXIONES FINALES}

El TJUE ha sido y es una institución clave en el proceso de integración europea. Posiblemente una de las razones de ello sea el activismo mostrado en su jurisprudencia. Con él ha impulsado la creación de una organización internacional con un grado de integración que ha llevado a la conceptualización de su naturaleza en términos ignotos y una realidad de prosperidad y paz europeas desconocida en la historia. Sin embargo, como todo activismo judicial, es fácil que despierte recelos con aquellos que no están satisfechos con sus decisiones, pero en casos extremos también desde quienes temen que los jueces dejen de obedecer al principio básico de su sometimiento a la ley.

El caso de la desafección de los tories británicos respecto al TJUE parece explicarse en términos de su argumentario político interno de más soberanía respecto a una organización y un proyecto que nunca han visto realmente como propios. El

58 Martín y Pérez de Nanclares, J., op. cit., p. 837.

59 Antón Guardiola, C., «TEDH. Sentencia de 30.06.2005, Bosphorus Airways, 45036/98 -Derecho Comunitario y Convenio Europeo de Derechos Humanos», Revista de Derecho Comunitario, núm. 28, 2007, pp. 943-957, p. 947.

${ }^{60}$ Como sucedió en el caso Bosphorus, citado supra. 
papel jugado respecto a la libre circulación y el acceso a las prestaciones sociales, o los derechos de los trabajadores desplazados por la libre prestación de servicios, parece mostrar una pérdida del equilibrio entre el impulso a la integración económica y los derechos de los ciudadanos en favor de la primera; pero que en la medida en que genera problemas de legitimidad por desafección con el proceso de integración puede acabar volviéndose en contra de dicha finalidad. Por último, el Dictamen que ha impedido la adhesión al CEDH se ha visto como un desafío importante a la función judicial de sometimiento al Derecho. Aunque es cierto que no es una novedad en el recorrido jurisprudencial del TJUE, no parece descabellado considerar que por el tema al que ha afectado debería suponer un problema de legitimidad mayor.

Recibido: febrero de 2018. Aceptado: abril de 2018 


\title{
LA NULIDAD DIFERIDA DE LAS LEYES EN CASO DE OMISIÓN DE INFORMES AUTONÓMICOS PRECEPTIVOS
}

\author{
Miquel Pons Portella \\ Abogado
}

\section{RESUMEN}

En el ordenamiento jurídico español, la nulidad se relaciona con la idea de invalidez radical y retroactiva. Sin embargo, sobre todo en estos últimos años, el Tribunal Constitucional viene haciendo uso de la posibilidad de retrasar la eficacia de una declaración de inconstitucionalidad, de modo que una ley nula siga siendo válida durante un determinado periodo de tiempo. La denominada «nulidad diferida» ha sido empleada recientemente en dos supuestos de infracción de la disposición adicional 3. a de la Constitución de 1978, sobre el régimen especial canario, lo que ha permitido que se ampliase su aplicación a otros casos de omisión, durante el procedimiento legislativo estatal, de informes autonómicos preceptivos.

PALABRAS Clave: nulidad diferida, leyes, declaración de inconstitucionalidad, comunidades autónomas, informes preceptivos.

\section{LAW'S DEFERRED NULLITY IN CASE OF OMISSION OF MANDATORY AUTONOMIC REPORTS}

\section{Abstract}

In the Spanish legal system, nullity is related to the idea of radical and retroactive disability. However, especially in recent years, the Constitutional Court has been making use of the possibility of delaying the effectiveness of a declaration of unconstitutionality, so that a null law remains valid for a certain period of time. The so-called "deferred nullity" has recently been used in two cases of infringement of the $3^{\text {rd }}$ additional provision of 1978 Constitution, about the Canary Islands special regime, which has allowed its application to be extended to other affairs of omission, during the procedure state legislature, of mandatory autonomic reports.

KEYwORDs: deferred nullity, laws, unconstitutionality declaration, autonomic communities, mandatory reports. 


\section{NOCIONES GENERALES SOBRE LA NULIDAD DIFERIDA}

La nulidad diferida se produce cuando se declara por parte del órgano competente la invalidez radical de un acto determinado, pero al mismo se pospone en el tiempo la plena eficacia de la indicada declaración. Por ello, el acto nulo sigue produciendo todos sus efectos hasta que se agota el plazo de diferimiento, durante el cual normalmente se habrá sustituido el susodicho acto nulo por otro nuevo y válido․

En una reciente Sentencia de 29 de marzo de 2017 (recurso contencioso-administrativo núm. 47/2014) ${ }^{2}$, la Sección 5. ${ }^{a}$ de la Sala Tercera del Tribunal Supremo ha reconocido que «desde la perspectiva de nuestro derecho interno una solución de esta naturaleza puede resultar extravagante, dado que en nuestro ordenamiento jurídico el concepto de nulidad de pleno derecho [...] se ha vinculado a la idea de invalidez radical ex tunc» (FJ 13..$^{\circ}$. Es decir: la carencia de efectos que se predica de cualquier acto nulo tiene alcance retroactivo. Lo ha recordado, en otra decisión reciente, la propia Sección 5. ${ }^{a}$ de la Sala Tercera: «La nulidad radical-explica el Alto Tribunal

${ }^{1}$ Díaz Revorio, F.J., «Tipología y efectos de las sentencias del Tribunal Constitucional en los procedimientos de inconstitucionalidad ante la reforma de la Ley Orgánica del Tribunal Constitucional español», en Ferrer Mac-Gregor Poisot, E. y Zaldívar Lelo de Larrea, A. (coordinadores), La ciencia del derecho procesal constitucional. Estudios en homenaje a Héctor Fix-Zamudio en sus cincuenta años como investigador del derecho, UNAM. IMDPC. Marcial Pons, México, 2008, tomo v, pp. 291-319. Según este autor, «en ciertas hipótesis de inconstitucionalidad sin nulidad, y particularmente cuando la falta de declaración de nulidad obedece a la finalidad de evitar vacíos legales, resulta necesaria una nueva intervención legislativa acorde con las previsiones constitucionales, que sustituya a los preceptos legales considerados inconstitucionales, y sin embargo mantenidos provisionalmente vigentes. En tales casos puede resultar conveniente no abandonar por completo la sanción de nulidad de la ley, sino tan solo retrasar ese efecto el tiempo suficiente para que el legislador proceda a aprobar una nueva regulación normativa. De ese modo, el tiempo de retraso en la aplicación de la nulidad es, en definitiva, el plazo del que dispone el legislador para la aprobación del nuevo precepto legal» (p. 311).

2 Con esta resolución, el Alto Tribunal resuelve el recurso contencioso-administrativo interpuesto por CEPSA contra el Acuerdo del Consejo de Ministros de 15 de noviembre de 2013, por el que se aprueba la asignación final gratuita de derechos de emisión de gases de efecto invernadero a las instalaciones sujetas al régimen de comercio de derechos de emisión para el periodo 2013-2020 y para cada año a cada instalación, publicado por Resolución de 23 de enero de 2014, de la Dirección General de la Oficina Española de Cambio Climático. La mercantil impugna, en concreto, las disposiciones relativas a una refinería de petróleo sita en San Roque (Cádiz). Ahora bien, las «partes personadas en el presente recurso manifestaron su conformidad con el hecho de que la resolución recurrida supone la aplicación al caso concreto y dentro del ámbito nacional de la Decisión 2013/448/ UE, aprobada el 5 de septiembre de 2013 por la Comisión, de forma tal que el debate procesal no se centra en analizar la corrección de la decisión del Consejo de Ministros por vicios o infracciones propias, sino que su enjuiciamiento está condicionado por la validez de la citada Decisión comunitaria de la que el Acuerdo ahora impugnado es una mera ejecución o traslación en el ámbito interno» (FJ 3..$^{\circ}$. Por ello, mediante Auto de 2 de julio de 2015, la Sala Tercera planteó ante el Tribunal de Justicia de la Unión Europea una cuestión prejudicial de validez contra la Decisión 2013/488/UE (FJ 6. ${ }^{\circ}$, que "fue resuelta mediante Auto de fecha 26 de octubre de 2016» (FJ 7. ${ }^{\circ}$. Así las cosas, la Sentencia de 29 de marzo de 2017 se centra en «resolver acerca de los efectos que tal decisión ha de tener sobre el procedimiento que nos ocupa» $\left(\mathrm{FJ} 10{ }^{\circ}\right)$. 
en una Sentencia de 2 de marzo de 2016 (recurso de casación núm. 1626/2015)³conlleva la pérdida de eficacia ex tunc (desde su origen), según el principio enunciado en los aforismos latinos quod nullum est, nullum producit efectum y quod ab initio vitiosum est, non potest tractu tempore convalescere» (FJ 7..$^{\circ}{ }^{4}$.

Ahora bien, volviendo a la Sentencia de 29 de marzo de 2017, «es lo cierto -prosigue la Sala Tercera- que la suspensión de los efectos de una declaración de invalidez de un acto o normativa [...] no resulta inusual en el ámbito de la justicia comunitaria. Si bien, con carácter general, el Tribunal de Justicia ha determinado que la interpretación de una norma comunitaria y su declaración de invalidez, pronunciadas en vía prejudicial, despliegan en principio efectos ex tunc, a contar desde el momento de su entrada en vigor [...], ello no es óbice para que, a título de excepción, atendiendo a consideraciones de seguridad jurídica, puedan tener efectos prospectivos» (FJ 13..$^{\circ}$. De hecho, en esta misma Sentencia que estamos comentando, la Sala Tercera tiene que hacer frente a las complejas consecuencias de un pronunciamiento de nulidad del Tribunal de Justicia de la Unión Europea cuyos efectos se limitan temporalmente «de modo que, por una parte, dicha declaración únicamente surta efectos tras un plazo de diez meses a partir de la fecha en que se dictó la Sentencia [...], con objeto de permitir que la Comisión adopte las medidas necesarias, $y$, por otra parte, no puedan impugnarse las medidas que hasta que termine dicho plazo se hayan adoptado de conformidad con las disposiciones anuladas» (FJ 8. ${ }^{\circ}$ ). Este tipo de decisiones se fundamentan en el segundo párrafo del art. 264 del Tratado de Funcionamiento de la Unión Europea, de acuerdo con el cual «el Tribunal indicará, si lo estima necesario, aquellos efectos del acto declarado nulo que deban ser considerados como definitivos" 5 .

${ }^{3}$ Dictada en el trámite de ejecución de la declaración de nulidad del Plan General de Ordenación Urbana de Valladolid en los ámbitos de la Fábrica de Piensos CIA y de la Azucarera Santa Victoria.

${ }^{4}$ En cambio, «el artículo L600-9 del Código Urbanístico francés permite al juez administrativo que conoce un recurso interpuesto contra un plan urbanístico, cuando el motivo alegado consiste en un vicio de procedimiento, suspender el procedimiento judicial y fijar un plazo en el que la Administración puede subsanar ese defecto. Durante ese período, el Plan recurrido sigue en vigor. Subsanado por la Administración el defecto de procedimiento, el juez resuelve el recurso». RenaU Faubell, F., «La nulidad "radioactiva” de los planes urbanísticos por defectos en el procedimiento de aprobación", Noticias Jurídicas, 10 de marzo de 2016, http://noticias.juridicas.com/conocimiento/ articulos-doctrinales/10946-la-nulidad-ldquo;radioactivardquo;-de-los-planes-urbanisticos-por-defectos-en-el-procedimiento-de-aprobacion/ (consultado el 6 de febrero de 2018).

5 Mangas Martín, A. y Liñán Nogueras, D.J., Instituciones y Derecho de la Unión Europea, 6. ${ }^{a}$ edición, Tecnos, Madrid, 2010, pp. 452-453. Como regla general, a la luz del primer párrafo del mismo art. 264 del Tratado de Funcionamiento, «la sentencia que declara nulo un acto posee una autoridad absoluta, desplegando los efectos de cosa juzgada material y formal. Además, la nulidad del acto produce, salvo la excepción que se mencionará, efectos ex tunc, [...] ya que se considera que el acto no ha existido y que los efectos jurídicos que haya desplegado deben ser eliminados». Pero, como hemos apuntado, el aludido segundo párrafo del art. 264 del Tratado «ha permitido al Tribunal de Justicia de la Unión Europea modular el efecto retroactivo de las sentencias de anulación en los supuestos de reglamentos y, también de otro tipo de actos declarados nulos», como «el acto de aprobación del presupuesto de la Unión adoptado por el Parlamento Europeo»; «en otros casos, el 
Pero es que «incluso nuestro Tribunal Constitucional -seguimos leyendo en la Sentencia de 29 de marzo de 2017 (FJ 14. ${ }^{\circ}$ ) - ha hecho uso de tal técnica», como ocurrió con la STC 13/2015, de 5 de febrero, que comentaremos más adelante. Al igual que la propia Sala Tercera, en realidad, que en su Sentencia de 22 de abril de 2014 (recurso contencioso-administrativo núm. 73/2013), tras declarar la nulidad "por vicios en su procedimiento de elaboración» del Real Decreto 1422/2012, de 5 de octubre, por el que se establecen las servidumbres aeronáuticas del aeropuerto de Lleida-Alguaire ${ }^{6}$, acordó «mantener, excepcional y provisionalmente, la eficacia de las servidumbres aeronáuticas establecidas [...], en tanto en cuanto no se apruebe un nuevo Real Decreto que sustituya al ahora anulado» ${ }^{7}$. El Tribunal justifica esta «limitación temporal -y excepcional- de la eficacia de nuestra Sentencia» por «razones imperiosas ligadas precisamente a la seguridad de la navegación aérea. En efecto, una vez comprobado que el régimen sustantivo de las servidumbres impuestas y de sus mecanismos de control (tanto para los actos como para los planes urbanísticos o de uso del suelo) es conforme a Derecho, la declaración de nulidad del Real Decreto 1422/2012 basada exclusivamente en motivos formales no puede tener como efecto inmediato que la navegación aérea con origen o destino en el aeropuerto de Lérida quede desprovista de las indispensables garantías de seguridad en atención a las cuales se prevén aquellas servidumbres (y su régimen de control preventivo). Aun cuando los arts. 71 y 72 de la Ley Jurisdiccional no contemplan de modo expreso la limitación de los efectos de las sentencias que acojan pretensiones de nulidad de los actos administrativos, la Sala estima que ante circunstancias excepcionales, y por razones muy cualificadas que atañen a la seguridad y a la vida de las personas, nada obsta a que se mantenga temporalmente la eficacia del acto anulado, en tanto es subsanado el defecto formal determinante de la nulidad de aquellos actos» (FJ 7.॰). La verdad, empero, es que a día de hoy el Real Decreto 1422/2012, de 5 de octubre, sigue en vigor sin cambios.

Tribunal ha admitido el mantenimiento de los efectos de una directiva declarada nula hasta la adopción de una nueva directiva que la sustituye».

${ }^{6}$ Según lo razonado por la Sala, «en la tramitación del Real Decreto 1422/2002 se ha omitido un trámite esencial, el de la audiencia de las administraciones locales y autonómica directa e inmediatamente interesadas y afectadas por unas medidas (la imposición de servidumbres sobre sus territorios) que limitan [...] el ejercicio de sus propias competencias, tanto las correspondientes al planeamiento urbanístico como a la ejecución de obras, actividades e instalaciones en sus respectivos territorios. La omisión de aquel trámite vicia de nulidad, desde el punto de vista formal, al Real Decreto mismo que ha dejado indefensas, en la fase previa a su aprobación, [tanto] a las corporaciones locales como el Ayuntamiento de Peralta de Calasanz» (FJ 2..$^{\circ}$.

7 BOE núm. 117, de 14 de mayo de 2014, p. 37716. 


\section{LA NULIDAD DIFERIDA EN LA PRÁCTICA DEL TRIBUNAL CONSTITUCIONAL}

Así las cosas, la nulidad diferida es una solución totalmente excepcional que queda reservada para supuestos en los que -como ha explicado, a propósito de la jurisprudencia del Tribunal Constitucional, la magistrada Encarnación Roca Trías en su voto particular a la STC 151/2017, de 21 de diciembre- «se trata de preservar bienes o valores que el Tribunal considera constitucionalmente relevantes y que justifican la desvinculación entre inconstitucionalidad y nulidad, siquiera durante un determinado período de tiempo». En la aludida STC 151/2017, por ejemplo, el Alto Tribunal difiere "hasta la convocatoria de un nuevo proceso de elecciones locales» la nulidad del párrafo tercero del art. 197.1 a) de la Ley Orgánica 5/1985, de 19 de junio, de régimen electoral general, en la redacción dada por la Ley Orgánica $2 / 2011$, de 28 de enero, con el fin de evitar «alteraciones en procedimientos de exigencia de responsabilidad política en curso por la ausencia de un régimen jurídico alternativo y respetuoso con la Constitución que cohoneste el principio de igualdad en el ejercicio de las funciones representativas y la prevención de los efectos perversos causados por el transfuguismo en los legítimos fines declarados por la norma» $\left(\mathrm{FJ} \mathrm{8.} .^{\circ}{ }^{8}\right.$. Y en la STC 195/1998, de 1 de octubre, para citar otro caso bien distinto, el mismo Tribunal dispuso que «la declaración de inconstitucionalidad de la Ley 6/1992, de 27 de marzo, por la que se declara Reserva Natural a las Marismas de Santońa y Noja no debe llevar aparejada la inmediata declaración de nulidad» para evitar «una desprotección medioambiental de la zona con graves perjuicios y perturbaciones a los intereses generales en juego y con afectación de situaciones y actuaciones jurídicas consolidadas» (FJ 5.०.).

${ }^{8}$ El voto particular de la vicepresidenta Encarnación Roca Trías se dirige justamente a denunciar la «imprudencia» cometida por el Tribunal Constitucional al «hacer un uso de la nulidad diferida que estimo inadecuado. De acuerdo con la finalidad a la que antes he hecho referencia, esta técnica sirve para preservar determinados valores o bienes a fin de evitarles la afectación que supone la declaración de inconstitucionalidad y nulidad de la norma que les da cobertura. Por eso, su aplicación exige determinar con claridad el bien cuya preservación reviste tanta entidad como para romper con la consecuencia lógica de la inconstitucionalidad de una norma, su nulidad y consiguiente expulsión del ordenamiento. En el presente caso, no alcanzo a comprender, ni la Sentencia lo explica, cuáles son los derechos, intereses, bienes o valores que tienen una relevancia constitucional tal que llevan a modular los efectos de nulidad propios de una sentencia de inconstitucionalidad. No cualquier valor o interés justifica el aplazamiento de la eficacia de la nulidad del precepto legal declarado inconstitucional. Por lo tanto, no ha quedado aquí acreditado que haya tal incidencia que justifique el mantenimiento de la vigencia de una norma inconstitucional durante casi ańo y medio». Más adelante agrega: "Creo que no se ha tenido en cuenta que esta Sentencia de nulidad diferida se ha dictado al resolver una cuestión de inconstitucionalidad, con lo que el órgano judicial va a verse obligado, en principio, a aplicar la norma declarada inconstitucional y que todavía no es nula». El magistrado Andrés Ollero Tassara discrepa, en su voto particular, en esta misma dirección: «La obvia inconstitucionalidad de la medida -afirma- ha de acarrear su nulidad e inmediata expulsión del ordenamiento jurídico». 
Esta necesidad de justificación casuística se debe a que -como se afirmara en la STC 45/1989, de 20 de febrero-, como norma general y «de acuerdo con lo dispuesto en la Ley Orgánica de este Tribunal (art. 39. 1), las disposiciones consideradas inconstitucionales han de ser declaradas nulas, declaración que tiene efectos generales a partir de su publicación en el Boletín Oficial del Estado (art. 38.1 de la LOTC) y que en cuanto comporta la inmediata y definitiva expulsión del ordenamiento de los preceptos afectados (STC 19/1987, FJ 6.') impide la aplicación de los mismos desde el momento antes indicado, pues la Ley Orgánica no faculta a este Tribunal, a diferencia de lo que en algún otro sistema ocurre, para aplazar o diferir el momento de efectividad de la nulidad» (FJ 11..$\left.^{\circ}\right)^{9}$. Ciertamente, según la mejor doctrina, «la previsión constitucional o legal expresa de este retraso da cobertura jurídica a una medida que, en otro caso, resultaría difícilmente justificable» ${ }^{10}$.

Precisamente por ello, durante la VIII Legislatura, se planteó la posibilidad de modificar el art. 39.1 de la Ley Orgánica 2/1979, de 3 de octubre, del Tribunal Constitucional con el siguiente contenido: «Cuando la sentencia declare la inconstitucionalidad, declarará igualmente la nulidad de los preceptos impugnados o cuestionados. No obstante, motivadamente y para preservar los valores e intereses que la Constitución tutela, la sentencia podrá declarar únicamente la inconstitucionalidad o diferir los efectos de la nulidad por un plazo que en ningún caso será superior a tres años $\aleph^{11}$. Este Proyecto de Ley Orgánica ${ }^{12}$, presentado por el Gobierno a finales de 2005, definía la regla que queda transcrita como un «aspecto novedoso" que "habilita al Tribunal Constitucional para conceder un plazo extraordinario de suspensión de la eficacia de la nulidad de los preceptos inconstitucionales a la espera de su sustitución por el legislador", pero sólo en el caso -como decíamos- de que «expresamente se justifique la concurrencia de algún interés constitucional que resulte protegido por la adopción de este efecto extraordinario». Pese a tales prevenciones, este "aspecto novedoso» fue rechazado en hasta tres enmiendas presentadas en el Congreso:

9 El ordenamiento constitucional de la República de Austria, por ejemplo, contempla expresamente el retraso de la "eficacia derogatoria» de sus sentencias, como han explicado en nuestra doctrina Gómez Corona, E., «El control de constitucionalidad de la ley en España. Análisis de la jurisprudencia constitucional (1980-2008)», Revista de Derecho Político, núm. 74, enero-abril 2009, pp. 263-288, (pp. 278-279, nota 30); y Díaz Revorio, op. cit., p. 311, según el cual en dicho país «la posibilidad de retrasar los efectos de la anulación de la ley tiene amparo constitucional expreso, pudiendo el tribunal constitucional disponer dicho retraso en los efectos de la sentencia de inconstitucionalidad, hasta un máximo de dieciocho meses».

${ }^{10}$ Díaz Revorio, op. cit., pp. 311-312.

${ }^{11}$ El tenor original -y aún vigente- de dicho precepto es como sigue: «Cuando la sentencia declare la inconstitucionalidad, declarará igualmente la nulidad de los preceptos impugnados, así como, en su caso, la de aquellos otros de la misma Ley, disposición o acto con fuerza de Ley a los que deba extenderse por conexión o consecuencia».

12 «Proyecto de Ley Orgánica por la que se modifica la Ley Orgánica 2/1979, de 3 de octubre, del Tribunal Constitucional». Boletín Oficial de las Cortes Generales, serie A, 25 de noviembre de 2005, núm. 60-1. Véanse especialmente las pp. 2 y 6. 
I. El Grupo Parlamentario Vasco (EAJ-PNV) arguyó que la nueva potestad del Alto Tribunal se funda en un "difuso criterio» y que «abre un panorama para los aplicadores de las normas, en primer término, y para la ciudadanía, en términos generales, confuso y vulnerable, toda vez que en el lapso de tiempo dilatado que se le otorga al legislador para reponer la ley declarada inconstitucional, los jueces y tribunales deberán aplicar una ley que no ha sido anulada o enfrentarse a una posible cuestión de inconstitucionalidad por inaplicar una ley que, si bien deviene inconstitucional, sigue vigente hasta su sustitución. Ello, sin entrar en otros supuestos en los que puedan afectarse derechos fundamentales. El legislador debe ejecutar las sentencias en el menor tiempo posible y no cabe que se le exima o atenúe tal obligación mediante privilegios que resultan totalmente contrarios a la seguridad jurídica. Lo que ha venido siendo excepcional -y altamente criticado- hasta la fecha, quiere pasar a ser "normal" si contemplamos que en los escasos supuestos en que se ha diferido la nulidad a la sustitución de la norma el legislador ha tardado más de lo habitual en cualquier proceso legislativo en aprobar la correspondiente norma ${ }^{13}$.

II. El Grupo Parlamentario Popular en el Congreso argumentó que la potestad que comentamos no era procedente "por coherencia con la posición constitucional que corresponde a las Cortes Generales. El Tribunal Constitucional no puede sustituir al legislador: facultarle para suplir lagunas normativas es atribuirle facultades legislativas, lo que es inconstitucional». Además, también apuntó que «el plazo de inconstitucionalidad con nulidad diferida es demasiado amplio, generando una enorme inseguridad jurídica» ${ }^{14}$.

III. El Grupo Parlamentario Catalán (Convergència i Unió) rehusó la inconstitucionalidad sin nulidad, en la medida en que «la introducción de que la declaración de inconstitucionalidad de una norma quede independizada de su nulidad, de forma absoluta y permanente, no encuentra apoyo en el art. 161 de la Constitución», pero no la nulidad diferida, que mantuvo en los términos propuestos por el Gobierno en su Proyecto ${ }^{15}$.

Finalmente, la modificación del art. 39 de la LOTC no fue incluida en el Informe de la Ponencia ${ }^{16}$, por lo que quedó fuera de la reforma que venimos comentando ${ }^{17}$. Y ello a pesar de que algunos autores se habían mostrado verdaderamente

13 Boletín Oficial de las Cortes Generales, serie A, 23 de febrero de 2006, núm. 60-7, pp. 31-32, enmienda núm. 24.

14 Ibidem., p. 45, enmienda núm. 57.

${ }^{15}$ Ibidem., p. 57, enmienda núm. 95.

16 Boletín Oficial de las Cortes Generales, serie A, 5 de diciembre de 2006, núm. 60-9.

17 Gómez Corona, op. cit., pp. 278-279 y nota 31. 
esperanzados ante este cambio legislativo ${ }^{18}$, al considerar que era necesario -en palabras del profesor Díaz Revorio- para resolver el «acuciante» problema de «la falta de cobertura legal expresa [...], o incluso, para ser más claros, de la prohibición legal expresa de toda medida que desvincule inconstitucionalidad y nulidad [...]. En este sentido, y teniendo en cuenta que en determinadas ocasiones este tipo de medidas puede presentarse como la opción "menos mala" en el sentido de menos alejada de la Constitución y más respetuosa con las competencias y funciones de otros poderes del Estado, la doctrina venía reclamando insistentemente la reforma de la LOTC para contemplar y permitir el uso de estos fallos en las sentencias sobre la constitucionalidad de la ley» ${ }^{19}$.

La verdad, empero, es que, en un análisis estadístico de 356 pronunciamientos de inconstitucionalidad efectuados por el Tribunal Constitucional desde sus orígenes hasta 2008, la profesora Esperanza Gómez Corona ha contabilizado tan sólo un total de siete fallos estimatorios con declaración de nulidad diferida ${ }^{20}$. Con posterioridad se han producido algunos más, como ya hemos visto, entre los cuales destacamos primeramente la STC 164/2013, de 26 de septiembre: el primer asunto en el que el Alto Tribunal difiere la nulidad de una ley tras declararla inconstitucional por haberse omitido durante su elaboración un informe autonómico de carácter preceptivo ${ }^{21}$.

18 Gómez Corona, op. cit., p. 279, aludiendo a la mentada STC 195/1998, incluso afirma que «no cabe sino felicitarse del atrevimiento del Tribunal Constitucional a la hora de actuar al margen de la propia LOTC, pues este quebrantamiento se compensa por la protección que se dispensa a estas zonas si se compara con el efecto que tendría la anulación de la normativa estatal sin más, aunque ello se hiciera con escrupuloso cumplimiento de lo establecido en la LOTC».

19 Díaz Revorio, op. cit., p. 308 y nota 15 . Ahora bien, según este mismo autor, «el plazo que la ley establece como máximo resulta un tanto excesivo, tanto desde la perspectiva del derecho comparado (el plazo máximo existente en Austria es la mitad), como si se tiene en cuenta la necesidad de no demorar, más allá del tiempo estrictamente imprescindible, la exigencia al legislador del cumplimiento de los mandatos constitucionales. Por ello creo que puede afirmarse que prácticamente cualquier modificación legislativa imaginable puede llevarse a cabo (mucho más cuando existen poderosas exigencias constitucionales para hacerlo) en un período bastante inferior a tres años» (p. 312).

${ }^{20}$ Gómez Corona, op. cit., pp. 266 y 270.

21 Requejo Pagés, J.L., Duque Villanueva, J.C., Ortega Carballo, C. y Ahumada Ruiz, M., "Doctrina del Tribunal Constitucional durante el tercer cuatrimestre de 2013", Revista Española de Derecho Constitucional, núm. 100, enero-abril de 2014, pp. 267-312, (pp. 288-289). Estos autores destacan que es poco "habitual» que "el Tribunal recurra a la "nulidad diferida"», lo que convierte la STC 164/2013 en un pronunciamiento «singular no sólo por las razones aducidas para justificar la excepción a la regla de la declaración de inconstitucionalidad y nulidad que fija el art. 39.1 LOTC, sino, sobre todo, porque por primera vez el Tribunal fija un plazo determinado (un ańo) para que comience a desplegar sus efectos la declaración de nulidad». 
Con la STC 164/2013, en concreto, el Tribunal declara la inconstitucionalidad de las normas impugnadas por el Parlamento de Canarias en el recurso núm. 2703-2011 -a saber: la disposición transitoria $8 .^{a}$ y las disposiciones finales $27 .{ }^{a}, 28 .^{a}$ y $30 .^{a}$ de la Ley $2 / 2011$, de 4 de marzo, de economía sostenible- al constatar «la omisión de toda audiencia previa a la Comunidad Autónoma de Canarias» (FJ 6. ${ }^{\circ}$ ).

La disposición adicional $3{ }^{a}$ de la Constitución española de 27 de diciembre de 1978, en efecto, establece que «la modificación del régimen económico y fiscal del archipiélago canario requerirá informe previo de la Comunidad Autónoma o, en su caso, del órgano provisional autonómico». El art. 46 del Estatuto de Autonomía de Canarias (Ley Orgánica 10/1982, de 10 de agosto) desarrolla este precepto constitucional al señalar, de entrada, que el régimen económico-fiscal especial de Canarias es "propio de su acervo histórico y constitucionalmente reconocido, basado en la libertad comercial de importación y exportación, no aplicación de monopolios y en franquicias aduaneras y fiscales sobre el consumo» (apartado 1). Este régimen - contempla a su vez el apartado 3 del mismo art. 46- «sólo podrá ser modificado de acuerdo con lo establecido en la disposición adicional $3 .{ }^{a}$ de la Constitución, previo informe del Parlamento Canario que, para ser favorable, deberá ser aprobado por las dos terceras partes de sus miembros». El art. 46.4 del mismo Estatuto aún agrega que «el Parlamento Canario deberá ser oído en los proyectos de legislación financiera y tributaria que afecten al régimen económico-fiscal de Canarias».

En el FJ $4^{\circ}$ de esta misma STC 164/2013, de 26 de septiembre, el Tribunal Constitucional ha tenido oportunidad de sintetizar su «cuerpo doctrinal consolidado» sobre la "garantía procedimental» que para el régimen especial canario establece la disposición adicional $3 .^{2}$ de la Carta Magna ${ }^{22}$ :

I. «Este informe [del Parlamento Canario] es exigible siempre que la norma estatal [...] suponga una modificación de los elementos que integran el régimen económico-fiscal de Canarias".

II. «Para que pueda entenderse que una norma está destinada a modificar el régimen económico y fiscal, resultando exigible el citado informe previo, hemos afirmado que basta con que se modifiquen algunos de los elementos que lo integran».

22 Elvira Perales y Gómez Lugo (coordinadores), Pajares Montolío, Fraile Ortiz y Espinosa Díaz, «Actividad del Tribunal Constitucional: relación de sentencias dictadas durante el tercer cuatrimestre de 2013", Revista Española de Derecho Constitucional, núm. 100, enero-abril de 2004, pp. 245-266, (p. 246). En este análisis se destaca la recapitulación de la «doctrina sobre el régimen económico y fiscal canario en el contexto de la DA 3. ${ }^{a}$ CE, ya desde la STC 35/1984: nulidad de los preceptos legales que afectan al régimen especial canario y que fueron aprobados sin respetar el trámite de audiencia previa a la Comunidad Autónoma previsto en su Estatuto de Autonomía». 
III. El informe en cuestión «no es vinculante, de manera que su sentido desfavorable no impide la modificación del régimen especial canario [...]; pero sí es preceptivo, por lo que su ausencia determina la inconstitucionalidad de la norma pertinente». Así ocurrió por vez primera, recuerda el Tribunal, con la STC 35/1984, de 13 de marzo, que declaró la inconstitucionalidad del Real Decreto-ley 1/1983, de 9 de febrero, por el que se deroga la exacción sobre el precio de las gasolinas de automoción «en todo lo que se refiere a las islas Canarias, normativa que en tal sentido se anula».

IV. «La misma consecuencia de inconstitucionalidad de la norma tiene la omisión de la "audiencia" a que se refiere el art. 46.4 del Estatuto de Autonomía de Canarias [...]. Ambos (informe y audiencia) son constitucionalmente exigibles cuando se dan los presupuestos de hecho contenidos en la norma».

v. «El momento idóneo para solicitarlo era antes de la tramitación de la iniciativa legislativa en las Cortes Generales, "justamente para que en ésta pueda tomarse en consideración el parecer del Parlamento canario". Ahora bien, ello no impide su solicitud en un momento posterior, que resulta además exigible, debiéndose incluso solicitar un nuevo informe cuando en dicho debate se introduzcan modificaciones que alteren el proyecto "tan radicalmente que no pueda tenerse por informado"».

En definitiva, «toda afectación o modificación del régimen [especial canario] [...] requieren para su aprobación bien de audiencia, bien que se solicite informe previo del Parlamento canario, informe y audiencia previa que no resultan vinculantes pero sí son preceptivos, de manera que la ausencia de su solicitud determina la inconstitucionalidad de la norma que modifique o afecte al régimen económico y fiscal canario».

La gran novedad de la STC 164/2013 estriba, como decíamos, en los «términos» de esta declaración de inconstitucionalidad, que quedan expresados en su FJ 7.․ Así, el Tribunal considera que "la nulidad inmediata que, como regla y de acuerdo con el art. 39.1 de la LOTC, sigue a un pronunciamiento de inconstitucionalidad, debe ser matizada en este caso concreto" por los siguientes motivos:

I. «Las disposiciones finales 27. ${ }^{\text {y }} 28$. $^{a}$ [de la Ley $2 / 2011$, de 4 de marzo, de economía sostenible] se aprobaron para reflejar las modificaciones a la Ley 37/1992, de 28 de diciembre, del impuesto sobre el valor añadido consecuencia de su adaptación al Derecho de la Unión Europea, por lo que no cabe descartar que su nulidad pudiera suponer también una infracción del mismo».

II. «La reserva para inversiones en Canarias, a que se refieren la disposición transitoria $8{ }^{a}$ y la final $30 .^{a}$, ha sido modificada precisamente para incentivar la realización de determinadas inversiones en esta Comunidad Autónoma, de acuerdo con la finalidad de su régimen especial, por lo que la anulación inmediata del precepto generaría previsiblemente un perjuicio directo a esta misma Comunidad».

Así las cosas, prosigue el Tribunal, «para cohonestar por un lado la exigencia procedimental del informe previo de la Comunidad Autónoma de Canarias, que 
viene establecida directamente por la Constitución, y, por otro, los propios intereses de la Comunidad Autónoma de Canarias, que podrían experimentar un perjuicio derivado de vacíos normativos, la nulidad derivada de la declaración de inconstitucionalidad debe quedar diferida por el plazo de un año, plazo que se considera razonable para que, en su caso, se sustituyan las normas declaradas nulas una vez observado el procedimiento constitucional del informe previo emitido por el poder legislativo de la Comunidad Autónoma de Canarias».

El Tribunal Constitucional recuperó esta modulación un año después, en la STC 164/2014, de 7 de octubre ${ }^{23}$, al resolver un nuevo recurso de inconstitucionalidad formulado por el Parlamento de Canarias: en esta ocasión, contra la disposición adicional 13. ${ }^{a}$ de la Ley 17/2012, de 27 de diciembre, de presupuestos generales del Estado para 2013, intitulada «subvenciones al transporte marítimo y aéreo para residentes en Canarias, Baleares, Ceuta y Melilla». Esta norma es nuevamente declarada inconstitucional y nula por infringir la "garantía procedimental» que regulan la disposición adicional $3 .^{\text {a }}$ de la Constitución y el art. 46 del Estatuto de Autonomía de Canarias, pero el Alto Tribunal decide "diferir los efectos de la nulidad, como también hicimos en la STC 164/2013" (FJ 3..$^{\circ}$. "Así», leemos en el pasaje final de la STC 164/2014, «debe establecerse una excepción a la nulidad inmediata que, como regla y de acuerdo con el art. 39.1 de la Ley Orgánica del Tribunal Constitucional, sigue a un pronunciamiento de inconstitucionalidad, para atender adecuadamente a otros valores con trascendencia constitucional como los derechos de los destinatarios de las subvenciones que se verían directamente perjudicados si la norma fuera declarada nula de forma inmediata. Por tanto, para cohonestar por un lado la exigencia procedimental del informe previo de la Comunidad Autónoma de Canarias, que viene establecida directamente por la Constitución, y, por otro, los intereses de los destinatarios de la norma, que podrían experimentar un perjuicio derivado de vacíos normativos, la nulidad derivada de la declaración de inconstitucionalidad debe quedar diferida por el plazo de un ańo a partir de la publicación de esta sentencia ${ }^{24}$, periodo de tiempo en el que se deberá proceder a sustituir las normas declaradas nulas una vez observado el procedimiento constitucional del informe previo emitido por el poder legislativo de la Comunidad Autónoma de Canarias» $\left(\mathrm{FJ} 3 .^{\circ}\right)^{25}$.

23 Requejo Pagés, J.L., Duque Villanueva, J.C., Ortega Carballo, C. y Ahumada Ruiz, M., «Doctrina del Tribunal Constitucional durante el tercer cuatrimestre de 2014», Revista Española de Derecho Constitucional, núm. 103, enero-abril de 2015, pp. 259-304, (pp. 276-277, 281, 285). La profesora Ahumada Ruiz señala como «la STC 164/2014 [...] siguiendo la pauta de la STC $164 / 2013$, reitera la novedosa práctica de diferir el efecto de la nulidad fijando al tiempo un plazo de un año para que se proceda a la sustitución de la norma declarada inconstitucional (por haber incurrido en un vicio de procedimiento determinante de la inconstitucionalidad)» (p. 285).

24 BOE núm. 262, de 29 de octubre de 2014.

25 En este asunto, además, el Tribunal también tuvo que precisar que «dado que la norma impugnada se refiere, de forma conjunta, a las subvenciones al transporte "para residentes en Canarias, Baleares, Ceuta y Melilla”, la citada declaración de inconstitucionalidad y nulidad debe limitarse a lo que de esta norma se refiere a los residentes en Canarias» (FJ 3..$^{\circ}$. 
Mientras que los preceptos de la Ley 2/2011, de 4 de marzo, de economía sostenible declarados nulos (diferidamente) por la STC 164/2013 nunca fueron «sustituidos", por lo que hoy -transcurrido con creces el plazo de un año concedido al efecto por el Tribunal- deben considerarse ineficaces, la disposición adicional $13{ }^{a}$ de la Ley 17/2012 sí fue «sustituida» del modo señalado por la STC 164/2014. En junio de 2015, el Ministerio de Fomento remitió al Parlamento de Canarias un «Proyecto de modificación de la disposición adicional décima tercera de la Ley 17/2012, de 27 de diciembre, de Presupuestos Generales del Estado para el año 2013, por la que se regulan las subvenciones al transporte, marítimo y aéreo, regular de pasajeros en lo que afecta a los residentes en Canarias». En su reunión del 14 de julio, la Mesa del Parlamento adoptó los acuerdos oportunos para proceder a la tramitación requerida "para dar cumplimiento a la Sentencia del Tribunal Constitucional 164/2014, de 7 de octubre, de acuerdo con lo establecido en el art. 46.3 del Estatuto de Autonomía ${ }^{26}$. Finalmente, el Pleno de la Cámara, en su reunión del 21 de julio de 2015, emitió «informe desfavorable» ${ }^{27}$. Lo cual no fue óbice para que la disposición final $10 .^{a}$ de la Ley 40/2015, de 1 de octubre, de Régimen Jurídico del Sector Público modificase en el sentido propuesto por el Gobierno la disposición adicional $13{ }^{a}$ de la Ley $17 / 2012$, porque -como ya hemos visto- «el informe exigido en la Constitución y la norma estatutaria, si bien es preceptivo, no es vinculante» [STC 164/2014, FJ 2. ${ }^{\circ}$, apartado b)].

\subsection{Los asuntos relativos al art. 72.3 del Estatuto de Autonomía de Aragón: LA STC 13/2015 y LA STC 155/2017}

La doctrina jurisprudencial sobre la disposición adicional $3 .^{\text {a }}$ de la Constitución que acabamos de exponer ha sido aplicada recientemente por el Tribunal Constitucional en un litigio relativo al art. 72.3 del Estatuto de Autonomía de Aragón (Ley Orgánica 5/2007, de 20 de abril), de acuerdo con el cual, «para la defensa de los derechos relacionados con el agua contemplados en el art. 19, la Comunidad Autónoma emitirá un informe preceptivo para cualquier propuesta de obra hidráulica o de transferencia de aguas que afecte a su territorio». El indicado art. 19 regula los «derechos en relación con el agua»: por un lado, la facultad de los aragoneses de «disponer del abastecimiento de agua en condiciones de cantidad y calidad suficientes para atender sus necesidades presentes y futuras, tanto para el consumo humano como para el desarrollo de actividades sociales y económicas que permitan la vertebración y el reequilibrio territorial de Aragón» (apartado 1); y, por el otro, la doble obligación de los "poderes públicos aragoneses» de velar por «la conservación y mejora de los recursos hidrológicos, ríos, humedales y ecosistemas y paisajes vinculados, mediante la promoción de un uso racional del agua, la fijación de cau-

26 Boletín Oficial del Parlamento de Canarias, núm. 11, de 17 de julio de 2015.

27 Ibidem, núm. 273, de 30 de agosto de 2016. 
dales ambientales apropiados y la adopción de sistemas de saneamiento y depuración de aguas adecuados» (apartado 2) y "para evitar transferencias de aguas de las cuencas hidrográficas de las que forma parte la Comunidad Autónoma que afecten a intereses de sostenibilidad, atendiendo a los derechos de las generaciones presentes y futuras» (apartado 3).

En su STC 110/2011, de 22 de junio, por cierto, el Tribunal Constitucional avaló expresamente el art. 72.3 del Estatuto de Autonomía de Aragón al considerar que «la emisión de informes preceptivos por parte de las Comunidades Autónomas en el seno de procedimientos estatales, o viceversa, ha sido considerada por la doctrina de este Tribunal [...] una técnica adecuada para los supuestos de concurrencia de competencias" (FJ 15. ${ }^{\circ}$ ). Se citan al respecto la STC 243/1993, de 15 de julio, y la STC 31/2010, de 28 de junio, entre otras (FJ 9. ${ }^{\circ}$ ).

Pues bien, las Cortes de Aragón promovieron en 2014 recurso de inconstitucionalidad contra la disposición adicional $15 .{ }^{a}$, la disposición transitoria $2^{\mathrm{a}}$, la disposición derogatoria única, apartado 3 , y las disposiciones finales $2 .{ }^{\mathrm{a}}, 3 .{ }^{\mathrm{a}}, 4{ }^{\mathrm{a}}{ }^{\mathrm{a}}$ y $5 .^{\mathrm{a}} \mathrm{de}$ la Ley 21/2013, de 9 de diciembre, de evaluación ambiental. En su STC 13/2015, de 5 de febrero $^{28}$, el Alto Tribunal declara la inconstitucionalidad de tales normas, por ser «contrarias» al art. 72.3 del antedicho Estatuto de Autonomía, al haberse omitido «el preceptivo trámite de audiencia a la Comunidad Autónoma de Aragón». Ahora bien, haciendo mención expresa de la STC 164/2013 y la STC 164/2014, «en ambos casos por referencia a la participación del Parlamento de Canarias», el Tribunal de nuevo modula los «términos» de la declaración de nulidad de un modo que ya conocemos:

La nulidad inmediata que, como regla y de acuerdo con el art. 39.1 de la LOTC, sigue a un pronunciamiento de inconstitucionalidad, debe ser matizada en este caso concreto ya que todas estas disposiciones se refieren al régimen de transferencias hídricas a través del acueducto Tajo-Segura, cuya trascendencia está fuera de toda duda de suerte que la anulación de las normas antes mencionadas es susceptible de generar graves perjuicios a los intereses generales. Por tanto, para cohonestar por un lado la exigencia procedimental del informe previo de la Comunidad Autónoma de Aragón, y, por otro, los propios intereses de las restantes Comunidades Autónomas afectadas por el trasvase y del resto de los destinatarios de la norma que podrían experimentar un perjuicio derivado de vacíos normativos, la nulidad

${ }^{28}$ Elvira Perales, Espinosa Díaz (coordinadores), Pajares Montolío, Fraile Ortiz, Gómez Lugo, «Actividad del Tribunal Constitucional: relación de sentencias dictadas durante el primer cuatrimestre de 2015", Revista Española de Derecho Constitucional, núm. 104, mayo-agosto de 2015, pp. 171-199, (p. 173); Requejo Pagés, J.L., Duque Villanueva, J.C., Ortega Carballo, C. y Ahumada Ruiz, M., "Doctrina del Tribunal Constitucional durante el primer cuatrimestre de 2015", Revista Española de Derecho Constitucional, núm. 104, mayo-agosto de 2015, pp. 201-242, (pp. 206 y 215); Blasco Hedo, E., "Jurisprudencia al día. Tribunal Constitucional. Aragón. Trasvase Tajo-Segura. Sentencia del Pleno del Tribunal Constitucional de 5 de febrero de 2015 (ponente: Luis Ignacio Ortega Álvarez)», Actualidad Jurídica Ambiental, 25 de marzo de 2015, disponible en <http://www.actualidadjuridicaambiental.com/jurisprudencia-al-dia-tribunal-constitucional-aragon-trasvase-tajo-segura/> (consultado el 13 de febrero de 2018). 
derivada de la declaración de inconstitucionalidad debe quedar diferida por el plazo de un año, a partir de la publicación de esta Sentencia, periodo de tiempo en el que se deberá proceder a sustituir las normas declaradas nulas una vez observado el procedimiento del informe previo emitido por la Comunidad Autónoma de Aragón [FJ 5. ${ }^{\circ}$, apartado e)].

En fechas más recientes, con su STC 155/2017, de 21 de diciembre ${ }^{29}$, el Alto Tribunal se ha pronunciado nuevamente sobre este mismo asunto, al resolver el recurso interpuesto por el Gobierno de la Comunidad Autónoma de Aragón contra la disposición adicional 5. a , la disposición transitoria única, la disposición derogatoria única y las disposiciones finales 1 . $^{a}$ y 2. ${ }^{a}$ de la Ley 21/2015, de 20 de julio, por la que se modifica la Ley 43/2003, de 21 de noviembre, de montes. Estas normas son «en todo idénticas a las declaradas inconstitucionales y nulas en la STC 13/2015 por haberse omitido, antes de su aprobación parlamentaria, el trámite de informe» (FJ 4..$^{\circ}$, como acabamos de explicar.

Así las cosas, la parte recurrente aduce en el caso resuelto por la STC 155/2017 una nueva infracción del art. 72.3 del Estatuto de Autonomía de Aragón, mas en esta ocasión, «a diferencia [...] de lo ocurrido en el procedimiento parlamentario enjuiciado en la STC 13/2015, la Cámara sí interesó [...] el informe de la Comunidad Autónoma, de modo que la discusión procesal se ha de entender objetivamente ceñida a si el informe se pidió de una manera regular y en términos tales que permitieran a aquélla manifestar con efectividad su criterio al respecto. Esto es lo que la demanda niega con el argumento de que el "escaso lapso de tiempo transcurrido hasta la aprobación de la ley" [...] desde que el repetido informe fuera interesado vino a impedir a la Comunidad Autónoma cumplir con este trámite» (FJ 4. ${ }^{\circ}$ ).

El Tribunal Constitucional afirma que «la actuación del Congreso de los Diputados merece, sin duda, algunos reproches» [FJ 7. , apartado a)], pero tal «cuestionable proceder, «matiza a continuación»,

no provoca, en sí mismo considerado, la inconstitucionalidad de las disposiciones de ley que en este recurso se pretende. La mencionada Cámara legislativa, a diferencia de lo planteado en el caso resuelto por la STC 13/2015, no omitió, sin más, la solicitud del informe autonómico, informe que fue efectivamente recabado. Por tanto, los preceptos impugnados sólo podrían llegar a considerarse incursos en invalidez si, atendida la tramitación desenvuelta en las Cortes Generales y las demás circunstancias relevantes, la atribución que establece el art. 72.3 del Estatuto de Autonomía de Aragón hubiera sido de imposible ejercicio o defensa por parte de las instituciones autonómicas, pues bien claro está que un vicio de procedimiento como el que aquí hemos constatado no habría de afectar finalmente a la ley, vicián-

29 Blasco Hedo, E., «Jurisprudencia al día. Tribunal Constitucional. Aragón. Trasvase Tajo-Segura. Sentencia 155/2017 del Pleno del Tribunal Constitucional, de 21 de diciembre de 2017 (Ponente: Fernando Valdés Dal-Ré)», Actualidad Juridica Ambiental, 13 de febrero de 2018, disponible en <http://www.actualidadjuridicaambiental.com/jurisprudencia-al-dia-tribunal-constitucional-aragon-trasvase-tajo-segura-2/> (consultado el 13 de febrero de 2018). 
dola a su vez, si la participación de la Comunidad Autónoma prevista en aquella disposición del Estatuto hubiera podido, pese a todo, ser ejercida o, cuando menos, invocada ante las Cámaras con alguna posible eficacia, de haberlo intentado así los correspondientes órganos de la Comunidad Autónoma» [FJ 7. ${ }^{\circ}$ apartado b) $]^{30}$.

Tras analizar las concretas circunstancias del caso, se concluye en la STC 155/2017, «el Tribunal no aprecia que, a lo largo de la tramitación en las Cortes Generales [...], la Comunidad Autónoma se hubiera visto privada, en todo momento y en términos absolutos, de la posibilidad de ejercer o, en su defecto, de hacer valer la atribución estatutaria (art. 72.3) que su Gobierno ahora invoca» (FJ 8..$^{31}$, de modo que procede la desestimación del recurso de inconstitucionalidad interpuesto ${ }^{32}$.

30 De hecho, la STC 155/2017 precisa que la «efectiva emisión» del informe autonómico no constituye "condición de intervención indispensable o necesaria para el perfeccionamiento de la ley. $\mathrm{Si}$, en efecto, el parecer autonómico hubiera sido oportuna y regularmente recabado y si la Comunidad Autónoma, en hipótesis, hubiera omitido la manifestación de su criterio en el plazo al efecto fijado, no por ello la prosecución del trámite legislativo sin ese informe determinaría que la ley finalmente aprobada hubiera nacido viciada, siendo inasumible la conclusión contraria, que supondría tanto como conferir a la Comunidad Autónoma un poder de veto ex silentio frente al ejercicio de la potestad legislativa del Estado sobre ámbitos de su exclusiva competencia. En definitiva, cuando corresponde a una u otra de las Cámaras, o a ambas, sucesivamente, interesar esta intervención autonómica, lo que está en juego con carácter prioritario es el debido respeto a la facultad de informar, mediante la necesaria solicitud al efecto. A resultas de tal respeto o transgresión sería de considerar la regularidad o irregularidad procedimental de la ley, de modo que solo cuando aquella necesaria solicitud no se hubiera realizado en absoluto [...] o cuando se hubiera llevado a cabo en términos tales que hicieran de todo punto imposible o ineficaz la intervención autonómica [...] cabría concluir en que habría resultado desconocida la atribución autonómica y viciada, por esta causa, la disposición de ley adoptada sin dar en absoluto ocasión a la Comunidad Autónoma de hacer llegar a las Cortes su criterio o, eventualmente, de defender y hacer valer, en curso aún el procedimiento legislativo, la propia atribución" [FJ 5. ${ }^{\circ}$, apartado b)].

${ }^{31}$ Los hechos enjuiciados en la STC 155/2017 son sintetizados del siguiente modo por el propio Tribunal: «La Comunidad Autónoma de Aragón fue requerida, aunque de modo y en circunstancias formalmente poco atentas, para emitir su informe. Y ni lo llegó a evacuar, pudiendo haberlo hecho ante el Senado, ni invocó tampoco ante las Cortes Generales, en curso todavía el procedimiento legislativo, el menoscabo de la atribución propia que hoy defiende, menoscabo que pudo acaso haberse reparado en aquel procedimiento y que no es dable aducir frente a la ley cuando, como aquí es de ver, no se intentó en modo alguno. Por consiguiente, no es razonable imputar a la actuación del Congreso de los Diputados un vicio de invalidez de las disposiciones de ley que se impugnan» (FJ 8..$^{\circ}$.

32 El magistrado Cándido Conde-Pumpido Tourón se opone a este fallo - y a su fundamentación- con un rotundo voto particular que concluye del modo siguiente: «Teniendo en cuenta el significado institucional de la previsión del informe (que, según la STC 13/2015, [...] "tiene por objeto establecer un mecanismo de cooperación en un ámbito en el que resultan afectados intereses estatales y autonómicos") y el rango de la norma que lo exige (norma institucional básica de una Comunidad Autónoma y, por tanto, perteneciente al bloque de la constitucionalidad), no puedo compartir la nula consideración que se refleja en la Sentencia hacia un mecanismo de cooperación del que tan necesitado está nuestro Estado autonómico para lograr la cooperación en el ejercicio de competencias, tanto del Estado como de las Comunidades Autónomas, que confluyen en el mismo espacio físico. El presente pronunciamiento desatiende tanto el principio de cooperación como el de lealtad institucional, principios que deben regir nuestro sistema autonómico para prevenir en lo posible 


\section{CONCLUSIONES}

a) Denominamos «nulidad diferida» aquel fenómeno jurídico que se produce cuando el órgano competente declara la invalidez radical de un acto determinado, pero al mismo pospone en el tiempo la plena eficacia de la indicada declaración. Es habitual el uso de este instrumento en la jurisprudencia del Tribunal de Justicia de la Unión Europea, en virtud del art. 264 del Tratado de Funcionamiento de la Unión, mientras que nuestro Tribunal Supremo todavía lo considera algo "extravagante».

b) El Tribunal Constitucional, pese a no contar con habilitación legal para ello, utiliza con cierta frecuencia este instituto, pero motivando siempre de modo preciso el valor o interés constitucional que pretende preservarse con su empleo y señalando, además, el plazo concreto de diferimiento. La doctrina ha considerado «conveniente» este expediente procesal ${ }^{33}$.

c) Un supuesto paradigmático de nulidad diferida en la jurisprudencia del Tribunal Constitucional suele darse cuando se declara la inconstitucionalidad de una ley por haberse incumplido un "trámite procedimental inexcusable» ${ }^{34}$ durante su elaboración: por ejemplo, la omisión de un informe autonómico preceptivo. En tales casos, como ha apreciado la misma doctrina, «el tiempo de retraso en la aplicación de la nulidad es, en definitiva, el plazo del que dispone el legislador para la aprobación del nuevo precepto legal $\aleph^{35}$.

d) Esta tipología de informes ha sido avalada como «un instrumento de cooperación mediante el cual la Comunidad Autónoma es llamada a intervenir en el curso de un procedimiento estatal a fin de hacer valer sus competencias e intereses, de principio afectados por el ejercicio de una competencia que corresponde, con todo, exclusivamente al Estado [...]. El trámite es preceptivo para el Estado, si bien el informe a emitir por la Comunidad Autónoma no es vinculante» (STC 155/2017, de 21 de diciembre, FJ 5..$^{\circ}$.

los conflictos. Quienes consideran que las deficiencias de nuestro Estado autonómico no provienen siempre, o solo, del contenido o la estructura del bloque de la constitucionalidad, sino también, en ocasiones, de la forma en que se interpreta ese bloque, obtendrán de la lectura de esta Sentencia respaldo a sus argumentos».

33 Díaz Revorio, op. cit., p. 311.

34 Tomamos la expresión del voto particular del magistrado Andrés Ollero Tassara a la STC 151/2017, de 21 de diciembre. En el mismo, se ensaya una clasificación de los supuestos más habituales de nulidad diferida en la jurisprudencia del Alto Tribunal: «Casos en los que se constataba que el legislador había omitido algún aspecto, lo que generaba la inconstitucionalidad de la norma (así, SSTC 138/2005, de 26 de mayo, y 273/2005, de 27 de octubre), o había incumplido un trámite procedimental inexcusable (SSTC 164/2013, de 26 de septiembre, 164/2014, de 7 de octubre, y 13/2015, de 5 de febrero, FJ 5 , por todas), o por inadecuación del instrumento normativo utilizado (SSTC 132/2010, de 2 de diciembre, y 164/2014, de 7 de octubre), o la inconstitucionalidad derivaba, no del contenido de la ley sino del incumplimiento de exigencias formales (SSTC 152/2014, de 25 de septiembre, FJ 6 b) 164/2014, de 7 de octubre, FJ 3) o de la imprevisión de aspectos materiales (STC 96/1996, de 30 de mayo, FJ 22 y 23)».

35 Díaz Revorio, op. cit., p. 311. 
e) Múltiples leyes del Estado han sido declaradas nulas por el Tribunal Constitucional al haberse omitido en su elaboración el «informe previo» que, para cualquier modificación del régimen especial de las Islas Canarias, exige la disposición adicional 3. ${ }^{a}$ de la Constitución de 1978. La STC 164/2013, de 26 de septiembre, y la STC 164/2014, de 7 de octubre, se insertan en esta senda jurisprudencial, pero con el matiz diferencial de emplear el expediente de la nulidad diferida "para cohonestar por un lado la exigencia procedimental del informe previo de la Comunidad Autónoma de Canarias, que viene establecida directamente por la Constitución, y, por otro, los intereses de los destinatarios de la norma, que podrían experimentar un perjuicio derivado de vacíos normativos» (STC 164/2014, de 7 de octubre, FJ 3. ${ }^{\circ}$ ).

f) La STC 13/2015, de 5 de febrero, sirvió para constatar que esta doctrina también resulta aplicable a otros supuestos en los que se exige un informe preceptivo autonómico, como ocurre con el art. 72.3 del Estatuto de Autonomía de Aragón. Mientras que la STC 155/2017, de 21 de diciembre, vino a frenar esta corriente al razonar que una norma de estas características «vincula, obviamente, a las instituciones y órganos del Estado en cada supuesto afectados. Pero también compromete a los titulares de este derecho de participación en orden a poner el debido celo en su ejercicio o a denunciar, llegado el caso, su merma en el curso del procedimiento en el que se padeció tal menoscabo. Si lo primero no se realizó, la ley, desde luego, no nació viciada [...]. Tampoco podría esperarse conclusión diferente, por lo demás, cuando no se reaccionó oportunamente frente a un proceder que, sin protesta previa alguna, se trae ante esta jurisdicción para solicitar la declaración de inconstitucionalidad de normas de ley» (FJ 8. ${ }^{\circ}$. 



\title{
ON THE TRADE-OFF BETWEEN THE RIGHT OF A DISABLED PERSON TO LIVE IN AN ACCESSIBLE ENVIRONMENT AND THE OBLIGATION TO PROTECT IMMOVABLE MONUMENTS IN POLISH LAW*
}

\author{
Tomasz Sienkiewicz** \\ The John Paul II Catholic University in Lublin
}

\section{Abstract}

The focus of this article is the competition of values that exists in the Polish legal system regarding adjustment of historic buildings to the needs of persons with disabilities. This is yet another case of the legal problem of choosing the superior value in the application of law. Numerous examples of situations in which friction between two competing values gives rise to practical problems are associated with subsidizing the removal of architectural barriers in listed historical buildings or heritage areas to meet the individual needs of persons with disabilities. On the one hand, there is the value of accessibility of buildings to the disabled, and on the other, there is the value of protection of monuments. The individual right of a person to free access to buildings is in competition with the right of the national community to respect the national heritage.

KEYwORDS: disabled person, administrative law, monument, human rights.

\section{EL DERECHO DE UNA PERSONA CON DISCAPACIDAD A VIVIR EN UN ENTORNO DE FORMA FUNCIONAL Y LA OBLIGACIÓN DE PROTEGER LOS MONUMENTOS INMUEBLES EN LA LEGISLACIÓN POLACA}

\section{RESUMEN}

En este artículo, el autor desea interesar al lector con el problema de la competencia de valores en el sistema legal polaco que se produce al adaptarse los monumentos históricos a las necesidades de los minusválidos. Muchas veces existe un problema legal de elegir un valor superior en la aplicación de la ley. Por ejemplo, cuando se subvenciona la eliminación de barreras arquitectónicas en relación con las necesidades individuales de personas con discapacidad, la situación es tal que cuando una persona discapacitada vive en un edificio inscrito en el registro de monumentos o en un edificio ubicado en un área inscrita en el registro de monumentos, surgen varios problemas prácticos, porque hay dos valores que compiten. Por un lado, el valor de la accesibilidad a las instalaciones de construcción para personas con discapacidad, por el otro, la protección de los monumentos. El derecho humano individual a la disponibilidad y accesibilidad de objetos de construcción compite con el derecho de la comunidad nacional a respetar el patrimonio nacional.

Palabras Clave: personas con discapacidad, minusválidos, derecho administrativo, monumento, derechos humanos. 
On 27th October 2017, a scientific conference was held at the John Paul II Catholic University of Lublin (KUL) ${ }^{1}$ to commemorate the 5 th anniversary of ratification by Poland of the Convention on the Rights of Persons with Disabilities. The event was co-organized by KUL, the Ministry of Family, Labour and Social Policy, and the State Fund for Rehabilitation of Disabled Persons. One of the subjects frequently discussed at the conference was accessibility of buildings to people with disabilities (Panel I on Public Space and Universal Design). The discussions demonstrated the relevance of this topic and the need for disseminating it in the academic community. And since the Convention is an international document, the problems of accessibility of public space to people with disabilities should not only be studied from the point of view of the national law, but also from the point of view of measures developed in this regard by other countries. Comparative studies and analyses should be carried out to investigate the possibilities of incorporating the best measures available into national systems, even though it is not always effective or possible to copy legal solutions from one country to another.

The focus of this article is the competition of values that exists in the Polish legal system regarding adjustment of historic buildings to the needs of persons with disabilities. This is yet another case of the legal problem of choosing the superior value in the application of law. Numerous examples of situations in which friction between two competing values gives rise to practical problems are associated with subsidizing the removal of architectural barriers in listed historical buildings or heritage areas to meet the individual needs of persons with disabilities. On the one hand, there is the value of accessibility of buildings to the disabled, and on the other, there is the value of protection of monuments. The individual right of a person to free access to buildings is in competition with the right of the national community to respect the national heritage.

Before discussing these values in detail, the question should be asked why we should be discussing the rights of persons with disabilities in the first place? Isn't the emphasis on the rights of this part of society exaggerated in the present times? Is it not a reaction against the evil that does not exist? Unfortunately, there are still

* The article was written as part of the project entitled "Prawne formy działania wojewódzkiego konserwatora zabytków" ("Legal acts of the provincial monument conservator," Reg. no. 2015/19/B/HS5/02525) within the framework of which research was funded by the National Science Centre, Poland (Narodowe Centrum Nauki). Quotations in the article, translated by the author into English, come from sources published in Polish. The term "provincial monument conservator" can also be translated into English as "voivodeship inspector of monuments," "Provincial Heritage Conservation Officer." Compare e.g. an English translation of the art 89 point 2 of the Act of 23 July 2003 on the protection and guardianship of monuments; on the Internet at: http://www.unesco.org/ culture/natlaws/media/pdf/poland/poland_act2302003_entof.pdf [Access: 10-12-2015-attentioninvalid legal status of the act].

** Doctor habilitatus in law, assistant professor in the Department of Administrative Law, Faculty of Law, Canon Law and Administration, The John Paul II Catholic University in Lublin; a Legal Counsel.

${ }^{1}$ Universidad Católica de Lublin Juan Pablo II. 
countries whose legislative systems do not respect human life as it is. In the history of humanity, there have already been states that did not observe the rules of human life. The important issues here are the world view and the philosophy of the functioning of the state, which either take into account the rules governing human life or not. Of special importance are the values respected in the legal system, as there does not exist a country with no value system. Most often, such systems are related to the dominant religion in the given territory. Even a state that declares itself completely separate from any church has a system of values that are enforced by the law. In the Polish doctrine, this dependence on axiology has been noted by many authors. For example, Łączkowski notes that "no state is able to avoid entering the fundamental domains of axiology, and therefore it always follows a certain world view. $^{2 \text { " }}$ There is no state whose legal system does not serve the realization of values. Some values are always there. They may be morally good or morally wrong. To say more, the law always expresses a view on the human being. Civil law (ius civile) expresses the sovereign's will and puts values into effect in social life. Sometimes the law embodies two different values which are morally good, and the realization of which requires balancing the scope of each of them in relation to specific facts.

To act in accordance with the law is therefore to act in such a manner so as not to rely merely on the unreflective execution of the formula contained in the law; the correct legalistic attitude in the application of the law takes into account

2 Łączkowski, W., Ograniczenia prawa stanowionego. [in:] Dęвı́́sкi A., Pomorska A., SMoleń, P. (eds.) W stużbie nauki prawa finansowego. Jubileusz obecności profesora Jana Gtuchowskiego w Katedrze Finansów i Prawa Finansowego Katolickiego Uniwersytetu Lubelskiego Jana Pawta II. Wydawnictwo KUL, Lublin, 2010, p. 71; cf. ŁĄCZKowsкI, W., Prawo a zmiana ustroju państwa. Wydawnictwo Naukowe Uniwersytetu Adama Mickiewicza, Poznań, 1992; ŁĄCzKowski, W., Granice prawa. [in:] Depo, W., Leszczyński, M., Guz, T., Marzec, P. (eds.), Veritatem in Caritate. Ksiegga Jubileuszowa z okazji 70. urodzin Ksiedza Biskupa Profesora Jana Śrutwy. Wydawnictwo KUL, Lublin, 2011, pp. 447-457; cf. on the influence of values on rationality of administrative decisions in: Sienkiewicz, T., Racjonalność decyzji administracyjnej. [in:] Marzec, P. (ed.), Servire veritati. Księga jubileuszowa z okazji siedemdziesiatych urodzin Profesora Kazimierza A. Ktosińskiego. Wydawnictwo KUL, Lublin, 2011, pp. 544-545. ZDYB, M., "Państwo prawa w perspektywie zaszłości historycznych oraz dokonujących się zmian.” [in:] Fundow ICz, S. (ed.) Wspótczesne problemy prawa publicznego. Studia z prawa publicznego, vol. 1, Lublin, 1999, p. 21; Cf. ZDYB, M., Prawny interes jednostki $w$ sferze materialnego prawa administracyjnego. Studium teoretyczno-prawne. Wydawnictwo Uniwersytetu Marii Curie-Skłodowskiej, Lublin, 1991, pp. 75-76. "Each legal norm has two sides: the essential one associated with literal wording of legal regulations and the existential one, which arises in relation to: a) axiological basis of the applicable legal system, natural order of things (natural law), principles of justice, righteousness of will, sense of law, etc.; b) facts of the case, to which law refers; c) supra-system norms, rules and principles which are a result of the civilization development (technical norms and standards, knowledge standards, praxeological principles, etc.); d) practices of law application (e.g. judicial decisions); e) doctrine views. A role of the organ of the state applying law is to identify the legal norm by referring not only to the situation and principle of conduct determined in a specific editing unit, but also by deducing a legal norm, taking into consideration the whole existential side of the legal rule and all-system rules. In such a reference system, each legal norm will be a system norm, and not a mechanical rule functioning separately from other rules, with the rejection of integrating values." 
the values conveyed in it. ${ }^{3}$ It is therefore important to verify which values related to the exercise of the rights of the disabled as well as the protection of heritage can be found in the Polish legal system. The Preamble to the Polish Constitution already states, among other things, that, we are to be "beholden to our ancestors for their labours, (...) for our culture rooted in the Christian heritage of the Nation and in universal human values," and also that we are "... obliged to bequeath to future generations all that is valuable from our over one thousand years' heritage," which is a direct reference both to Christian heritage and universal human values. Taking this into account, it should be noted that the circle of Christian culture embraces:

1. Respect for human life.

2. Respect for human heritage, especially national heritage, which, by virtue of its role of strengthening national identity, should be protected by the law of each State. ${ }^{4}$

In addition, attention should be paid to the rules related to the human life itself. The basis of human rights is dignity. An additional justification for human rights are the regularities of human life. Human beings do not create these regularities but only discover them, find that they exist $-\mathrm{a}$ fact from which the human rights of the disabled can be derived. The mode of human existence should also be the basis for the introduction of human rights into the legal system (positivism).

There is therefore a need to ask the question whether every human being is always fully functional (abled)? What are the criteria of "complete functionality?" This is not an analysis of the legal concept of "disabled person," but an attempt to answer the question whether human existence is characterized by periods of incomplete functionality. The question of disability is the question of the mode of human existence, also as a biological being subject to the laws of nature. The mode of human existence involves periods when the human being needs the help of others. No one is self-sufficient. Since in the course of human existence there occur periods when one needs the support of others (childhood, old age, sickness, etc.), this social dimension of human functioning has to be taken into account by those who govern the community. One should point out the regularities of human life associated with the dilemma indicated in the title of this article. This is not an exhaustive list of rules, of course, but an indication of those that are most relevant to the subject.

It should be noted that periods of incomplete functionality are part of human life. So the human rights of the disabled are simply human rights. We call them the rights of people with disabilities, to better accent them, but disability potentially affects every person as a biological being. In addition, every human being faces the

3 Cf. Ziembiński, J., Wstęp do aksjologii dla prawników. Wydawnictwo Prawnicze, Warszawa, 1990, p. 135 - "It turns out that legalism cannot in fact be treated as a purely formal attitude, for in speaking of respecting the law we speak of respecting a law that holds in regard certain fundamental values."

${ }^{4}$ Comp. Cf. Constitution of the Republic of Poland, art. 6, section 1. 
risk of losing fitness, because a person is unable to maintain total control over sudden events or processes (especially those initiated during the early period of life as a defenseless child). In the context of this topic, it is important to note the fact that inherent to human life is creative ability and some of the manifestations of this creativity become important to the whole national community due to social interest.

In connection with the above mentioned rules, the following questions should be asked:

- Do legal norms protect the life of the human being or the "superior human being?" - Can any life be "a life unworthy of living?"

A suitable example here is that of Nazi terror against mentally ill people. "From 1939 to 1941 more than 100 thousand mentally ill German citizens died in gas chambers 5 . Cases of murdering mental patients also occurred in the period in which Art. 211 of the Penal Code, which provided for the death penalty for a premeditated killer $^{6}$ (as amended by the Act of 4 September 1941) was in force.

Taking the above into account, the separation of the rights of people with disabilities is not a defense against the utopian state nor a theoretical hypothesis. Unfortunately, it has been experimentally tested how a state that does not respect in its actions the regularities of human life as it is acts? For this reason, to speak of the rights of people with disabilities is not speaking in exaggerated terms or speaking against an evil that does not exist, but rather a consequence of discerning the brutal reality of some real systems. Therefore, it is important to move from the human rights contained in the works of the legal doctrine to positive regulation of human rights of the disabled at the international and then national level.

Moving to the Polish legal system and the discussed competition of values, it should be noted that, apart from the Preamble to the Constitution of the Republic of Poland, the obligation to protect national heritage is stipulated in Art. 5 of this document which provides, among others, that "the Republic of Poland shall (...) safeguard the national heritage and shall ensure the protection of the natural environment pursuant to the principles of sustainable development." Moreover, Art. 6 clause 1 stipulates that the "Republic of Poland shall provide conditions for the people's equal access to the products of culture which are the source of the Nation's identity, continuity and development." Obligations to persons with disabilities are provided for in Art. 69 of the Constitution of the Republic of Poland in the following wording: "Public authorities shall provide, in accordance with statute, aid to disabled persons to ensure their subsistence, adaptation to work and social communication.”

5 Ternon, Y., Helman, S., Eksterminacja chorych psychicznie w III Rzeszy. Od teoretyków narodowosocjalistycznych do praktyków z SS. Państwowy Zakład Wydawnictw Lekarskich, Warszawa, 1974, p. 31.

${ }^{6}$ Ibidem, p. 14 et seq., 321 
The inherent and inalienable dignity of the person shall constitute a source of freedoms and rights of persons and citizens. It shall be inviolable. The respect and protection thereof shall be the obligation of public authorities" as stipulated in art. 30 of the Constitution. Recognition that humanity and dignity are inextricably linked is the starting point for the formulation of human rights. John Paul II believes that "the dignity of the human person is a transcendent value, always regarded as such by all who sincerely seek the truth. Indeed, the whole history of mankind must be interpreted in the light of this certainty." Human dignity is closely related to natural law and human rights.

A distinction is made between human dignity and personal dignity. While the latter can be lost, the former is inalienable. It is a characteristic that defines every human being. It describes a special human property. Dignity is identified with the value of a human being in general. It is an expression of human nature. It is not subject to gradation. It is tantamount to humanity. ${ }^{8}$ It is granted in the same way to every human being, also in relation to other people. It precedes the man-made legal order. Dignity is the natural law that people receive with their nature. ${ }^{9}$ Disabled people -including those mentally retarded-also have this inalienable trait of dignity. Article 30 of the Constitution of the Republic of Poland stipulates that "the inherent and inalienable dignity of the person shall constitute a source of freedoms and rights of persons and citizens. It shall be inviolable. The respect and protection thereof shall be the obligation of public authorities." The legislator appreciated the importance of human dignity, raising it to the rank of a constitutional norm. Moreover, as stipulated in the Preamble to the Polish Constitution, all who apply the Constitution for the good of the Third Republic, shall do so "paying respect to the inherent dignity of the person." Human dignity is the source of human rights and the guarantee that these rights will be respected.

Human rights are closely related to natural law. Often the enactment of the rights of persons with disabilities is a condition for the exercise of their right to life. An example of such a situation is the right of a disabled person to live in an accessible physical environment. ${ }^{10}$ Definitions of human rights are related to different concepts of the human being, philosophy and law. These rights are justified through the prism of morality or the laws of nature. Human rights are the specific expression of values that need no justification ${ }^{11}-$ such as the right to life. Positive law does not cre-

7 Jan Pawee II, Oredzie na światowy dzień pokoju, 1999. [quoted from :] Rynio, A., Solidarność w nauczaniu Jana Pawta II. Wybór tekstów. Fundacja Servire Veritati Insty tut Edukacji Narodowej, Lublin, 2005, p. 65.

${ }^{8}$ Cf. ibidem, pp. 103-104. KrąPIEc, M.A., Cztowiek i prawo naturalne. Dzieta X. Wydawnictwo KUL, Lublin, 1993, p. 140.

9 Cf. Kość, A., Podstawy filozofii prawa. "Petit”, Lublin, 2001, p. 192.

${ }^{10}$ Cf. Sienkiewicz, T., Prawo cztowieka niepetnosprawnego do życia w środowisku uksztattowanym funkcjonalnie. Wydawnictwo Polihymnia, Lublin, 2004, pp. 21-28.

${ }_{11}$ Cf. Dutkiewicz, P., Problem aksjologicznych podstaw prawa we wspótczesnej polskiej filozofii i teorii prawa. Wydawnictwo Uniwersytetu Jagiellońskiego, Kraków, 1996, p. 88. 
ate human rights, but at best affirms and protects them. ${ }^{12}$ "The purpose of human rights is to protect the citizen from the state (status negativus), to ensure his political participation (status activus), as well as provide him with social or even cultural benefits (status positivus). ${ }^{13}$ In an administrative-and-legal relation, this protection represents an important value, because the relation is characterized by inequality of the parties." The disability of a client at an office renders this inequality even deeper.

Human rights have three basic characteristics: universality, inalienability and inviolability. This entails that they do not have their source in state regulations.

Theories of human rights are connected with theories of the law of nature. The theories of natural law, according to Kość, can be broadly divided along the lines of four main points of view:

1) Theories which require that the principles or norms of natural law have immutable, universal and timeless validity (an absolute, static natural law), and theories that postulate that natural law has only temporal, situational, and hence variable validity (variable, dynamic natural law);

2) Theories that cover entire, more or less closed, systems of norms of natural law (natural law systems), and others that only cover common principles, treating them as natural law (natural law principles);

3) Theories that are based on the diverse bases of validity of natural law: the order of being, the nature of the human being, the nature of things, the principles of justice;

4) Theories that consider natural law to be valid and those for which natural law is merely a conceptual idea, but an obligatory law of duty, i.e, the law that gives effect to positive law. ${ }^{14}$

Not so long ago, the socialist doctrine rejected all non-legal grounds for civil rights. In the Marxist tradition, human rights were associated with human duties, with the the latter having primacy over the former. ${ }^{15} \mathrm{~A}$ democratic state of law cannot make the incorporation of human rights in its legislative order contingent upon positive law. In accordance with Article 2 of the Polish Constitution, the Republic of Poland is "a democratic state ruled by law and implementing the principles of social justice."

An interesting concept of human rights has been presented by Höffe. In his view, human rights have a chance to play a role in commutative justice (justice in exchange). Human rights involve reciprocity (exchange) of rights and duties. "Only when I receive from others benefits that must be reciprocated, does the responsi-

12 Cf. ibidem, pp. 88-89. Höffe O., Etyka państwa i prawa. Wydawnictwo Znak, Lublin, 1992, pp. 65-66.

${ }_{13}$ Zob. Höfre, O., op. cit., p. 99.

${ }_{14}$ Kość, A., op. cit., p. 255.

15 See. Dutkiewicz, P., op. cit., pp. 91-93. 
bility of a human being rest on me. And inversely, I have the human right when I actually provide a benefit that requires mutual exchange of benefits.

A situation like this takes place where there is an interest that cannot possibly be renounced, which can only be achieved by mutual effort. One is then no longer free to say whether they accept the exchange or not. When interests exclude the possibility of resignation, then the entities cannot but cooperate; one cannot withdraw from an exchange of this type. ${ }^{16}$

The rationalist theory of natural law derives from the belief in the unchangeable nature of man. It postulates that, first, one must find out what the existing order of human existence is and then follow the rules determined by this order. ${ }^{17}$ The order of human existence gives rise to the laws of nature which are human rights.

An interesting view of the laws of nature has been presented by Ziembiński. According to him, the concept of laws of nature in the broad sense should be understood as including all "concepts of law as a set of norms, which assume that valid legal norms are norms that have not been established or recognized as valid by a state organization, even if such recognition only means that the organization sanctions the overstepping of those norms. ${ }^{18}$

A document that is of fundamental importance for the protection of human rights is the United Nations' Universal Declaration of Human Rights of 1948, which assumes that human dignity is the basis of human rights. Human dignity is independent of the will of a state or an individual. Dignity was in fact the only concept accepted by all negotiators of the Declaration. ${ }^{19}$ Human dignity is inherent and inalienable. It does not depend on the degree of a person's physical or mental fitness. It is the foundation of justice. If a state is to be fair, dignity must be taken into account in the legislative process and statutory interpretation. ${ }^{20}$

The rights of people with disabilities are included in the Charter of the Rights of Persons with Disabilities. It is a resolution of the Sejm of the Republic of Poland, which constitutes a legal guideline for legislators to implement the principles of social justice with regard to people with disabilities (the above mentioned resolution of the Polish Sejm does not constitute a source of universally binding law in Poland). The norms of positive law which enact the rights of the disabled, are found in various legal acts in many domains of life, because the life of a person with a disability, just as the life of a fully functional or abled persons, is not homogeneous.

The resolution does not contain a closed catalogue of the rights of persons with disabilities, but instead highlights those rights which are particularly important from the point of view of the disabled person. These include the right to access to goods and services, the right of access to treatment and medical care, the right

16 HöfFe, O., op. cit., p. 110.

17 See Kość, A., op. cit., p. 186.

18 Ziembiński, Z., Wstęp do aksjologii dla prawników. Wydawnictwo Prawnicze, Warszawa, 1990, p. 139.

${ }_{19}$ Cf. ibidem, p. 95.

${ }^{20}$ Cf. ibidem, pp. 102-103. 
to access to social rehabilitation, the right to education, the right to assistance in obtaining qualifications, the right to work, the right to social security, the right to life in the environment without functional barriers, the right to have an autonomous representation of one's own group, the right to full participation in public, social, cultural, artistic and sports life as well as in leisure and tourism.

In $₫ 1$ of the Charter of the Rights of Persons with Disabilities, the Sejm stated that these persons "have the right to lead an independent and active life and may not be discriminated against ... this in particular means the right of people with disabilities to ... live in an environment free from functional barriers, in particular:

- Free access to offices, polling stations and public facilities,

- Free movement and general use of means of transport,

- Free access to information,

- Opportunities for interpersonal communication.”

Another important norm, from the point of view of administrative law, is the norm provided for in the above-mentioned Charter which stipulates that the disabled have the right to participate fully in public and social life.

Persons with disabilities should receive special protection from a just law-abiding state, as they are society's weaker members. By virtue of dignity enjoyed by every human being, they have the same right to life and development as fully functional individuals. One element of social justice is the system of equal opportunities which guarantees that weaker members of society have the same opportunities as strong individuals. ${ }^{21}$ Unfortunately, the rights of people with disabilities are not fully or consistently exercised. It is sufficient to note, in connection with the fundamental and inalienable right to life, which is the right of every human being, including a disabled person, that the principles cited above are clearly violated in Polish legislation concerning grounds for abortion. While Article 38 of The Constitution of the Republic of Poland stipulates that The Republic of Poland shall ensure the legal protection of the life of every human being, ${ }^{22}$ the Polish law sanctions inequality in the possibility of exercising one's right to life as early as at the stage of fetal life. ${ }^{23}$ It is worth noting, however, that if a state does not unconditionally respect the right to life of every human being-irrespective of their weaknesses, disabilities, or usefulness- then it does not guarantee the right to life that is inherent to every human being ${ }^{24}$ to any of its citizens. The state does not grant

${ }^{21}$ Cf. Styczeń, T., Wprowadzenie do etyki. TN KUL, Lublin, 1995, p. 193, in the context of the right of weaker (unborn) members of society to life.

22 Cf. Wiśniewski, L., Wolności i prawa osobiste w Konstytucji RP z 1997 roku i w prawie międzynarodowym. "Terra," Poznań, 1998, p. 7.

${ }^{23}$ On the grounds for permissibility of termination of pregnancy in the Polish law, see Art. 4a of the Act of 7 January 1993 on Family Planning, Human Embryo Protection and Conditions of Permissibility of Abortion (Journal of Laws No.133, item 78 with later amendments).

${ }^{24}$ Cf. Strczeń, T., op. cit., p. 192. 
this law, but instead recognizes and affirms it. ${ }^{25}$ An unconditional acceptance of the right to life should be part of our legal order, because "it is only when none of the littlest ones has to fear our democracy, that we all will not have to worry about the shape of our democracy. ${ }^{26}$ "The debate that sometimes takes place in various European countries about the acceptability of abortion or euthanasia is actually a debate about the philosophy of human life adopted in the legislation of those countries and the primacy of the right to comfort (quality of life) over the right to life or vice versa.

The Convention on the Rights of Persons with Disabilities (Journal of Laws of 2012, item 1169), promulgated into Polish law by the Act of 15 June 2012 on the Ratification of the Convention on the Rights of Persons with Disabilities drawn up in New York on 13, December 2006 (Journal of Laws item 882) recognizes the human right to live in an environment free from accessibility barriers. This is stipulated in Article 9.

The right to live in an environment free from accessibility barriers enables a person with a disability to exercise their right to life. To the fully functional members of society, this Article guarantees appropriate living conditions (comfort) or is an element of the right to safety (e.g. fire safety). Living in an environment free from accessibility barriers is one of the human rights of the disabled that follows also from the principles of social justice. It was expressly stated in Article 1 clause 8 of the Charter of the Rights of Persons with Disabilities approved by the resolution of the Sejm of the Republic of Poland of 1 August 1997 (Official Gazzette of the Republic of Poland No. 50, item 475). Architectural, urban, transport, communication and technical barriers make it difficult, and often impossible, for people with disabilities to enjoy the right to life and to meet their needs on a par with the abled. The problem of overcoming accessibility barriers affects not only people with motor dysfunctions, but also people who are blind, visually impaired, deaf, hearing impaired, mentally handicapped, or affected by cardiovascular, respiratory and other defects. The circle of people who are interested in living a life without accessibility barriers is large then.

A disabled person moving in a wheelchair will consider a lack of an elevator in the apartment block in which they live an architectural barrier The daily self-service activities, which abled people perform automatically not giving them much thought, can sometimes be a challenge to a person with a disability that is beyond their capabilities. Accessibility barriers in disabled people's environment can prevent social and medical rehabilitation, make it impossible for them to get a job and meet their basic life needs. A person with a disability, separated from the world by a kind of obstacle course, is at the mercy of third parties, while often they could easily meet their needs themselves, were their surroundings better adapted to

${ }^{25}$ Cf. ibidem, p. 198.

26 Ibidem, p. 199 
their capabilities. The state should strive to eliminate accessibility barriers, because, even though their removal often requires substantial financial outlays, an inclusively designed environment reduces the costs society has to bear in other areas, such as social assistance. It is impossible to neglect the positive effects that removal of such barriers also has on the psychological well-being of the disabled.

It should be noted that the actual application of the right of a disabled person to live in an environment free from accessibility barriers is the basis for the exercise of other human and civil rights. The right of disabled persons to access goods and services cannot be exercised if, for example, a store in which they wish to do their shopping has too narrow a door to accommodate a wheelchair. In the same way, the right of access to treatment and medical care cannot be used in a hospital that is not disabled-friendly. Similarly, access to social rehabilitation may be limited when, for example, there are no funds for adapting rooms for occupational therapy workshops to the needs of the handicapped. The right to education or the right to assistance in obtaining qualifications cannot be exercised in the absence of adequate school building conditions, which unfortunately is the case in a large part of Polish schools. For the same reason, the right to work may remain just a postulate, considering that few work sites apart from supported employment establishments, are accessible to people with disabilities and not many new, suitably adapted facilities are being opened. The right to full participation in social, cultural, artistic, sport and leisure activities and tourism may remain in the sphere of declarations without appropriately arranged spaces and technical facilities. The examples can be multiplied endlessly.

For many years, housing estates, communication routes, and public buildings had been designed without paying attention to the needs of the handicapped, while the arrangement of space is an important element influencing the quality of life of those persons. Space should be developed and arranged keeping in mind the criteria of accessibility, recognizability and usability. ${ }^{27}$ The actual application of these criteria is the exercise of the right to life without accessibility barriers.

The requirements concerning spatial planning that takes into consideration the needs of people with disabilities as well as the preservation of cultural heritage can be found in the legal definition of spatial order. Whenever the Act on Spatial Planning and Land Use Management makes reference to "spatial order," "this is to be understood as a configuration of space that creates a harmonious whole and takes into account, in a structured way, all the functional, socio-economic, environmental, cultural and structural-and-aesthetic conditions and requirements" (Article 2 clause 1). This Act requires that spatial planning and land use management activities should take account of numerous important conditions, among which are "the requirements for the protection of cultural heritage, monuments and modern cultural assets" and "the requirements for the protection of health and

${ }^{27}$ Ostrowska, M., Cztowiek a rzeczywistość przestrzenna. Oficyna Wydawnicza Nauka i Życie, Szczecin, 1991, p. 219. 
safety of people and property and the needs of persons with disabilities" (Article 2, clauses 4 and 5). There are also cases in which the Polish law requires co-operation between the Provincial Heritage Conservation Officer and local government bodies in determining land use management rules for the area under the administrative control of a given local government. For example, when a borough/town/ city council has passed a resolution on preparing a zoning study, the borough leader (wójt), the town mayor (burmistrz) or the city mayor (prezydent miasta) "asks for expert opinions on the solutions adopted in the study," including the opinion of a "competent Provincial Heritage Conservation Officer" (Article 11 item 6 point c). After the council has passed a resolution on preparing the local zoning plan, the borough leader, town mayor or city mayor, among the many actions set out in Art. 17 of this Act, moves for the plan to be reviewed and accepted by "the competent Provincial Heritage Conservation Officer with regard to building and land development." Before the council passes a resolution on the principles and conditions of arranging street furniture, billboards, advertising equipment and fences, their dimensions, quality standards and types of construction materials which they can be made from, the borough leader/mayor is obliged to immediately have the $\mathrm{draft}$ resolution reviewed, also by the Provincial Heritage Conservation Officer "with regard to building and land development" (Article 37b clause 2 item 4). According to Art. 38b clause 2 item 2 point c, "The Provincial Board, before submitting the draft landscape audit for adoption by the Provincial Assembly" "will consult the draft," among others, with the Provincial Heritage Conservation Officer. According to Art. 53 clause 4 item 2, "Decisions referred to in Art. 51 clause 1 (on the location of public purpose investments), will be issued upon review by the Provincial Heritage Conservation Officer regarding sites and buildings protected by conservation measures referred to in Art. 7 of the Act of 23 July 2003 on the Protection and Guardianship of Monuments, and sites and buildings included in the Borough Register of Listed Structures."

The construction-related aspects of the competition that exists between heritage value and accessibility needs are manifested in procedures concerning:

1. Granting of a building permit issued under the Construction Law Act, when works are to be carried out at a listed building or in its vicinity;

2. Execution of construction works under a pre-construction notification as defined in the Construction Law Act, when works are to be carried out at a listed building or in its vicinity;

3. Granting a permission to conduct construction works at a listed structure under the Protection and Guardianship of Monuments Act;

4. Removal of accessibility barriers (primarily architectural barriers) in connection with the individual needs of people with disabilities under the Act on occupational and Social Rehabilitation and Employment of Persons with Disabilities;

5. Obtaining the legal status of a supported employment establishment, as defined by the provisions of the Act on Occupational and Social Rehabilitation and Employment of Persons with Disabilities; 
6. Obtaining the legal status of an occupational activity establishment, as defined by the provisions of the Act on Occupational and Social Rehabilitation and Employment of Persons with Disabilities;

7. Obtaining the status of a rehabilitation centre, as defined by the provisions of the Act on Occupational and Social Rehabilitation and Employment of Persons with Disabilities.

This is not an exhaustive catalogue of examples. It should be added in passing that important provisions regarding the adjustment of newly constructed buildings to the needs of people with disabilities (especially public buildings and multi-family buildings which are designed to be used by many people) can be found in the Regulation of the Minister of Infrastructure of 12 April 2002 on the Technical Conditions of Buildings and their Location (uniform text: Journal of Laws of 2015, item 1422) ${ }^{28}$.

There are many situations in which the human right of a disabled person to live in an accessible environment and the obligation to preserve historical heritage must be taken into account in considering evidence or interpreting the law. The Construction Law Act (hereinafter referred to as: Construction Act) refers to the above-mentioned criteria in many places. The obligations toward people with disabilities are already mentioned in the provisions regarding the design and construction of civil engineering structures. Pursuant to Art. 5 clause 1 item 4 of the Construction Act: "A structure as a whole and its individual parts, together with related construction equipment, shall be designed and constructed, taking into account the anticipated period of use, in the manner specified in the relevant provisions, including technical and building regulations and principles of technical knowledge, in order to secure [...] necessary conditions for use of public facilities and residential multi-family housing by persons with disabilities, and in particular persons using wheelchairs." The right of accessibility of buildings to disabled people is mentioned already with reference to the legal requirements regarding the contents of the project itself. According to Art. 34 clause 3 item 2 of the Construction Act, an architectural and construction design describing the function, shape and structure of a building, its characteristics as to energy consumption and environmentalissues, should contain proposals of necessary technical and materials solutions in order to illustrate theprinciples of adapting the structure to its environment, and in relation to structures referred to in Art. 5 clause. 1 item 4 -such a design should also include a description of accessibility of the building to the disabled (4) necessary conditions for the use of public facilities and residential multi-family housing by persons with disabilities, and in particular persons using wheelchairs]. Sometimes, it is necessary to change an approved building design, which often leads to the question whether

${ }^{28}$ Cf. for example $\$ 9-\$ 21$ of the Regulation of the Minister of Labour and Social Policy of 27 November 2007 on Rehabilitation Programmes (Journal of Laws No.230, item 1694 with later amendments). 
the proposed changes are substantial or not. The legislator in Art. 36a clause 1 provides that "Substantial departure from the approved building design or other conditions covered by the building permit shall be admissible only after obtaining a decision changing the building permit from the competent architecture and building administration body." Next, Art. 36a clause 5 item 5 stipulates that "Insignificant departure from the approved building design or other conditions of the building permit shall not require obtaining a decision on amendment of the buildingpermit and shall be admissible unless it concerns: ... ensuring the conditions necessary for the object to be used by disabled persons [emphasis mine ].

At times, it is necessary to make exceptions to the application of technical and building regulations, however, in some cases, such exceptions must be made keeping in mind the need to ensure accessibility of buildings to the handicapped as well as heritage conservation requirements. Pursuant to Art. 9 of the Construction Act.

1. In particularly justified cases, the application of technical and building regulations, referred to in Article 7, may be renounced. Such renunciation may not endanger human life or safety of property, while in the case of buildings mentioned in Article 5, clause 1, item 4, it may not restrict the access of disabled people to those buildings, nor shall it cause deterioration of health and sanitary conditions, utility requirements, as well as the state of the natural environment, after fulfilling certain substitutive requirements.

2. Upon receiving an authorisation from the minister, who set forth the technical andbuilding regulations, the competent authority shall, by a decision, either refuse or grant the permit regarding the renunciation of the said regulations.

3. The application to the minister referred to in paragraph 2 , regarding authorization to grant consent for the renunciation of regulations, shall be submitted by a competent authority prior to the issue of the building permit decision. The said application shall contain:

a) A description of the features of the object and, where necessary, the plot or land development design, and if the renunciation may affect the natural environment or the neighbouring real estate, also development designs for these real estate properties, taking into account the existing and projected housing development;

b) Detailed justification of the necessity to renounce the application of the said regulations;

c) Proposals for substitutive solutions;

d) A positive opinion of the Provincial Heritage Conservation Officer in respect of listed buildings and other buildings located in the areas subject to conservation protection;

e) Where necessary, a positive opinion of other authorities concerned.

4. The minister referred to in paragraph 2, may make the issue of permits for the saidrenunciation contingent upon the fulfilment of additional requirements" [emphasis mine]. 
At the same time, attention should be paid to the situation in which one norm of the Construction Act allows action under a pre-construction notification while another, lex specialis, requires a building permit. Pursuant to Art. 29 clause 1 item 18 of the Construction Act "The construction of [...] ramps designated for disabled persons [...] shall not require a building permit." Simultaneously, clause 4 of the same Article stipulates that said works.

1) require a building permit when carried out at a listed structure,

2) or the notification referred to in Art. 30 clause 1 when carried out in a listed conservation area.

-with the reservation that the building permit and the pre-construction notification must be accompanied by a permit from the competent Provincial Heritage Conservation Officer, issued on the basis of regulations on the protection and guardianship of monuments." This refers to the permit issued under Art. 36 clause 1 of the Act on the Protection and Guardianship of Monuments, which stipulates that, among many types of permits, the execution of construction works at a listed building or in its vicinity requires a permit from the Provincial Heritage Conservation Officer (Article 36 clause 1 items 1 and 2 of the Act on the Protection and Guardianship of Monuments). The requirement that certain construction activities performed at a civil engineering structure must be accepted by heritage conservation authorities is mentioned in Art. 39 of the Construction Act:

1. The performance of construction work concerning a listed structure or a listed conservation area shall be subject to obtaining, prior to issue of the building permit decision, the permit for conducting the said work issued by the competent Provincial Heritage Conservation Officer.

2. A permit to demolish a listed structure may be issued after obtaining a decision of the Chief Heritage Conservation Officer, acting on behalf of the minister competent for culture and protection of national heritage, on removal of the said object from the register of monuments.

3. With regard to buildings and structures which are unlisted nationally but are covered in a Borough Register of Built Heritage, the building permit or the permit to demolish a structure shall be issued by thecompetent authority in consultation with the Provincial Heritage Conservation Officer.

4. The Provincial Heritage Conservation Officer shall be obliged to express his opinion regarding the application for a permit to build or demolish the structures referred to in paragraph 3 within 30 days from the day when it was served. Failure to express an opinion within this time limit shall be considered as lack of objections as to the design solutions presented in the application... [emphasis mine].

As the regulations quoted above show, the right of people with disabilities to free access to buildings and structures and the right of the national community to preserve the national heritage are intertwined, and a public administration body 
has to seek a balance of obligations between the legitimate interest of a party and social interest. With regard to decisions on issuing a building permit, the register of building permit applications and building permit decisions includes information on "arrangements with the Provincial Heritage conservation Officer concerning the date of sending the documents to the Officer, date of receipt of the review and the number of days required for the review of documents "(Art. 86b clause 3a item 2point i of the Construction Act).

The competent authority shall carry out, when summoned by the investor, a mandatory inspection of the construction in order to ascertain that it was conducted in compliance with the approvals and conditions specified in the building permit" (Article 59a clause 1 of the Construction Act). This inspection includes verification of:

1) Compliance of the building with the plot development or land development design;

2) Compliance of the building/structure with the architectural and construction design in terms of $[. .$.$] ensuring the conditions necessary for the building$ structure to be used by disabled persons, in particular persons using wheelchairs - with respect to public buildings and multi-family residential buildings" (Article 59a clause 2 items 1 and 2 point $\mathrm{f}$ of the Construction Act).

The legislator has also taken account of situations in which a building or structure is not suitable for renovation. A problem arises when the building/structure is a historical monument. Pursuant to Art. 67 clauses 1-4 of the Construction Act:

1. If an unused or unfinished building is not suitable for renovation, reconstruction or completion, the building authority shall issue a decision ordering the owner or administrator to demolish the building and put the site in order. The said decision shall specify the dates of commencement and completion of these activities.

2. The provisions of clause 1 do not apply to listed buildings and structures.

3. In relation to unlisted buildings subject to conservation protection under a local spatial development plan, the decision referred to in clause 1 shall be issued by building supervision authorities subject to prior agreement with the Provincial Heritage Conservation Officer.

4. The Provincial Heritage Conservation Officer is obliged to express his opinion within 30 days. Failure to do so within the time allowed shall be considered an agreement."

To resolve a conflict of values is to proceed according to the procedure established in, among others, the Code of Administrative Procedure. Currently Polish administrative law is mainly based on so-called first generation of administrative procedures, although it is gradually being modified. Likewise, the construction permit granted on the basis of the Construction Law Act (Art. 28), and the permit for construction works at a monument or in its surroundings, granted on the 
basis of the Law on Protection and Guardianship of Monuments (Art. 36 , clause 1 , item 1 and 2) seem to be the fruit of a first generation of procedures. However, in the case of determining the scope of application of values pertaining to the right of a disabled person to live in a functionally accessible environment and the protection of immovable monuments, it would be worth considering if, in the Polish administrative law on rendering administrative decisions pursuant to construction law and protection of monuments, there are such aspects of the discussed issue which could constitute a basis for applying procedures similar to those which were described by Barnes as a third generation of administrative procedures. ${ }^{29} \mathrm{I}$ am purposefully using the term "similar to" with reference to those proceedings, since the Polish law shall oblige a public administration body to strictly obey the law, and all types of negotiations and reconciliation of standpoints are limited by law. Moreover, granting a construction permit pursuant to the Construction Law Act, and permit for construction works at a listed structure/building (or in its surroundings) pursuant to the Act on the Protection and Guardianship of Monuments exercise norms of substantive law. Both decisions are rendered by two different public administration bodies (starosta, Provincial Heritage Conservation Officer). Pursuant to Art. 7 of the Constitution of the Republic of Poland "The organs of public authority shall function on the basis of, and within the limits of the law," and pursuant to Art. 6 of the Code of Administrative Procedure "Public administration bodies shall act in accordance with the law." In many cases law refers to extralegal

29 Barnes, J., “Towards a Third Generation of Administrative Procedures,” First draft -2016 Conference on Comparative Administrative Law April 29-30, 2016, https://law.yale.edu/ system/files/area/conference/compadmin/compadmin16_barnes_towards.pdf [01.11.2017], pp. 2-3: “... the third generation of administrative procedures consists of a collaborative method for making individual decisions and for rules and regulations, in which other administrative or private actors not only collaborate in varying degrees in the process to gather the relevant information, but also participate in one or more of the procedural stages, and in which these procedures are open to develop new solutions that are not previously foreseen by the law (i.e., environmental impact assessment, strategic environmental assessment procedures in the EU, or environmental permit procedures2). Rules and decisions to be made are not discovered in the law, but rather invented or created in the procedure. Procedural requirements may be imposed to private parties participating in the regulatory cascade." Cf. BARNES, J., "Introduction reform and innovation in administrative procedure." http://en.globallawpress.org/wp-content/uploads/Book2IntroENG.pdf [01.11.2017]. Cf. BArNEs, J., "Tres generaciones del procedimiento administrativo.” Derecho PUCP. Revista de la Facultad de Derecho No 67, 2011, http://revistas.pucp.edu.pe/index.php/derechopucp/article/view/2992/3508 [05.11.2017]. Cf. BARnes, J., "Procedimientos administrativos de tercera generacion,” https://revistas-colaboracion. juridicas.unam.mx/index.php/opera-prima-derecho-admin/article/viewFile/1428/1329 [06.11.2017]; Cf. BARNÉs VÁZqUEZ, J., "El procedimiento administrativo y el gobierno electrónico," http://repositorio.gobiernolocal.es/xmlui/bitstream/handle/10873/968/claves12_08_barnes.pdf?sequence=1, pp. 95-100, [06.11.2017]. Cf. KMIECIAK, Z., "Idea procedur administracyjnych trzeciej generacji (na przykładzie postępowania w sprawie dofinansowania projektów w ramach programów operacyjnych)," Państwo i Prawo 5/2015. Cf. Ćwiklińska, M., "Trzy generacje postępowania administracyjnego a Kodeks postępowania administracyjnego," ActaUniversitatisLodziensis. Folia Iuridica 75, 2015, http://dspace.uni.lodz.pl:8080/xmlui/bitstream/handle/11089/17022/4-041_050-\%C4\%86wikli\% $\mathrm{C} 5 \% 84$ ska.pdf?sequence $=1 \&$ isAllowed $=\mathrm{y}$. 
systems or does not directly specify criteria for evaluation of evidence in evidentiary process, before rendering the decision. Such situation occurs in the case of a permit for construction works at a listed structure/building, where the procedure specifies the body rendering an administrative decision (Provincial Heritage Conservation Officer), the formal grounds for initiation of administrative proceedings, formalization of an administrative decision, but there are no grounds for evaluation of evidence. Right there arises an opportunity to apply a procedure of evaluation of the aforementioned evidence in a way similar to application of a third generation of administrative procedures, whereas public administration bodies shall be constantly bounded by law. This bounding is necessary, since a procedure shall be aimed at decision equity and legal safety of both a public administration body and an administratively and legally subordinate entity.

Equity of an administrative decision ${ }^{30}$ cannot be considered without application of a procedure that shall provide a resolution of proceedings which might be considered equitable. Even the most noble premises might be undermined by the procedure whose aim cannot be considered equitable. Modus operandi might be contrary to the aim. The procedure, i.e. a manner of achieving the final effect in a form of an administrative decision, might or might not support the equity formula applied in a given legal system. This is also manifest in a procedure that has features that make it possible to realize the equity formula. If a public administration body is endowed with competitive values, a different manner of formalization of grounds and the extent of formalization of an administrative decision that goes beyond basic elements, indicated in Art. 107 of the Code of Administrative Procedure as applicable within the same legal condition, there occurs a situation which might exert a particularly adverse effect on the opportunity to reach an equitable decision.

A public administration body being bound by law is not necessarily tantamount to leaving a party in the proceedings in an entire dependence on the aforementioned organ. A number of rules included in the Code of Administrative Procedure encourage flexibility of procedure and ensure legal safety of a party. The aforementioned rules include the rule of taking all necessary steps to clarify the facts of a case and to resolve it, not only by request of a party but also ex officio, having regard to the public interest and the legitimate interests of members of the public (Art. 7 of the Code of Administrative Procedure), the rule of cooperation of public administration bodies during the proceedings, to the extent necessary to clarify the facts and legal status of the case, having regard to public interest and the legitimate interests members of the public and effectiveness of proceedings, by means of measures adequate to character, circumstances and complexity of the case (Art. 7b of the Code of Administrative Procedure), the rule of conducting proceedings in such a way as to increase the trust of citizens in public authority, having regard to the rules of proportionality, impartiality and equal treatment (Art. $8 \$ 1$ of the Code of Administrative Procedure). "Public administration bodies are required to

${ }^{30}$ Cf. Sienkiewicz, T., Racjonalność decyzji..., op. cit. 
provide full and proper information to the parties regarding the factual and legal circumstances which may affect the establishment of their rights and the obligations that are the subject of the administrative proceedings. The bodies shall take care to ensure that parties and other persons involved in proceedings do not suffer any loss owing to ignorance of the law and shall therefore provide the necessary clarifications and advice" (Art. 9 of the Code of Administrative Procedure). "Public administration bodies are required to ensure that parties are actively involved in each stage of proceedings and they shall allow the parties to express an opinion on the evidence and materials collected and the claims filed", and it is only possible to derogate from this rule when "resolution of the case requires urgent attention because of threats to human life or health or the threat of irretrievable material damage", and such derogation shall be recorded in the case file, by way of annotation (Art. 10 of the Code of Administrative Procedure). Moreover, "Public administration bodies should explain to the parties the basis for the rules used to decide a case, so that a decision may be implemented by the parties without the need for coercive measures" (Art. 11 of the Code of Administrative Procedure). The Code of Administrative Procedure specifies also proceedings aimed to settle disputes. Pursuant to Art. 13 of the Code of Administrative Procedure:

$\$ 1$. Public administration bodies, in cases whose character allows for that, aim for settlement of disputes and establishing rights and obligations which are subject of proceedings in the cases within their competence, and, in particular, by taking steps:

1) to induce the parties who have a conflict of interests to agree a settlement;

2) necessary to conduct mediations.

$\$ 2$. Public administration bodies take all reasonable steps at a given stage of proceedings, which allow for mediation or settlement, and, in particular, provide explanations concerning opportunities and benefits of amicable settlement.

There are also such situations where mediation might be a way of establishing the scope of individual values protected by law. Mediation is applied when character of a case allows for that (the Code of Administrative Procedure Art. 96a-96n). Pursuant to Art. 96a $\$ 3$ of the Code of Administrative Procedure "Aim of mediation is to explain and consider factual and legal circumstances of case, and make arrangements pertaining to resolving it within the existing law, including resolving the case by means of decision or settlement," and its participants might be not only parties involved in the proceedings, but also the body conducting proceeding and party or parties (Art. 96a \$4). "If, as a result of mediation, there are arrangements made pertaining to resolution of the case within the existing law, a public administration body resolves the case according to those arrangements, included in the mediation protocol" (Art. 96n $\$ 1$ of the Code of Administrative Procedure). Having regard to Art. 36 of the Act on the Protection and Guardianship of Monuments, 
there are significant opportunities to apply mediation in the situation when legislator has not directly expressed grounds for evaluation of evidence, but they shall be specified, by means of interpretation of the law, on the basis of a legal definition of monument or a statutory definition of monument protection.

While discussing the issue of competition of values, it needs to be noticed that protection of monument, due to public interest, arises from the definition of monument itself. Polish Act on the Protection and Guardianship of Monuments differentiates between immovable, movable and archaeological monument. The Polish word "zabytek" has a wider context than the English word "monument." In Polish the word "zabytek" does not only mean immovable monument. The law on protection and guardianship of monuments provides a definition of a monument in art 3 point $1-4$.

1) Monument -immovable or movable object or part of group thereof, made by man or connected with man's activity and constituting a testimony to a past era or event, the preservation of which is in the interest of society due to its historical, artistic, scientific or academic value.

2) Immovable monument-immovable object or part or group of objects referred to in point 1 .

3) Movable monument -movable object or part or group of objects referred to in point 1.

4) Archaeological monument -immovable monument constituting surface, underground or underwater remains of human existence or activity, composed of cultural accumulations and works or traces thereof contained in these accumulations, or a movable monument constituting such work. ${ }^{31}$

In addition to this, the legislator, in the title of the Act on the Protection and Guardianship of Monuments differentiates between 'protection' and 'guardianship'. The division into protection of monuments and guardianship of monuments represented a contribution to formulation of critical remarks ${ }^{32}$. Pursuant to Art. 4 of

31 http://www.unesco.org/culture/natlaws/media/pdf/poland/poland_act2302003_entof. pdf [[Access: 06-11-2017 -attention-invalid legal status of the act, but the definition of monument is currently acceptable] Art. 3

1) Monument -immovable or movable object or part of group thereof, made by man or connected with man's activity and constituting a testimony to a past era or event, the preservation of which is in the interest of society due to its historical, artistic, scientific or academic value;

2) Immovable monument -immovable object or part or group of objects referred to in point 1 ;

3) Movable monument -movable object or part or group of objects referred to in point 1;

4) Archaeological monument -immovable monument constituting surface, underground or underwater remains of human existence or activity, composed of cultural accumulations and works or traces thereof contained in these accumulations, or a movable monument constituting such work.

32 Normative differentiation between "protection" and "guardianship" has been subject to criticism -cf. ZeIdLer, K., O wtaściwy ksztatt stużby ochrony zabytków w Polsce. Postulaty de lege 
the aforementioned Act, the protection of monuments consists in, in particular, undertaking activities, by the public administration bodies, with the aim to:

1) Ensure legal, organizational and financial conditions that enable permanent preservation of monuments as well as their development and maintenance;

2) Prevent threats that may decline monuments' value;

3) Foil the destruction or improper use of monuments;

4) Counteract thefts, getting lost, or illegal export of monuments;

5) Check the state of preservation and the use of a monument;

6) Plan and develop the space, and shape the environment with the consideration of protection tasks.

Definition of guardianship of monuments is included in Art. 5 of the Act on monuments. As defined in the provisions thereof, the guardianship of monument by its owner, or its proprietor consists, in particular, in ensuring conditions for:

1) Scientific research and documentation of a monument;

2) Carrying out conservation, restoration and construction works at a monument;

3) Pprotection, and maintenance of a monument and its surroundings in the best possible state;

4) Use of a monument in a way ensuring permanent preservation of its value;

5) Popularization and dissemination of knowledge on a monument, and its historical and cultural significance.

Therefore, having regard to public interest in protection of monuments, legal norms shall be prepared in such a way that monuments are preserved for future generations, and, at the same time, subjective rights of proprietors of monuments are respected. At the same time, there arises the question, which extralegal systems of values, not indicated directly, might be determined within the process of interpretation of concepts 'protection of monuments' and 'guardianship of monuments'. A good example of this type of norms arising from extralegal law is conservational theory, which is not directly mentioned in the Act on the Protection and Guardianship of Monuments. Therefore, it is worth mentioning the rules of the aforementioned theory, according to Rouba, which will be useful in the process of application of many norms of the Act on the Protection and Guardianship of Monuments. "The fundament of contemporary theory of conservation-restoration, developed with difficulty over the centuries, and, in particular, in the last century, is imperative of individual treatment of each monument -based on scientific grounds for deep understanding of its essence, condition, establishing diagnosis and searching for appropriate treatment. The imperative of individual treatment of monument is, by no means, tan-

ferenda. [in:] Gardocka, T., Sobczak, J., (ed.) Prawna ochrona dóbr kultury. Wydawnictwo Adam Marszałek, Toruń, 2009, p. 34. 
tamount to arbitrariness of treatment. It means searching for solutions that allow for preserving monument for future generations in the possible unchanged condition, together with all its values" 33 [emphasis mine]. Rouba mentions seven rules of conservation, such as the following:

1) Primum non nocere;

2) Maximum respect for original substance of monument and all the values (material and non-material) thereof;

3) Minimum of essential interference (restraining from unnecessary actions);

4) In accordance with the above, this (and only this) that has a destructive impact on the original, shall be removed;

5) Clarity and differentiability of interference, and their aesthetic subordination to the original (non-competitiveness);

6) Reversibility of methods and materials;

7) Conducting all the works to the best of our knowledge and at the highest level. ${ }^{34}$

Therefore, legal system shall be endowed with such norms that allow for acting in accordance with rules of conservation. The Act on the Protection and Guardianship of Monuments does not directly refer to theory of conservation, which constitutes, for an office employee writing, e.g. an administrative decision, a difficulty in formulation of factual and legal resolution (see Art. 107 of the Code of Administrative Procedure).

Rules of conservation theory refer to actions on the object - monument itself, but values of regulation should be searched for in a much broader context, not only in the monument itself. In the center of axiology of the Act on the Protection and Guardianship of Monuments there is indeed a man and enhancing his relationship with national community. In the center of axiology of the Act on the Protection and Guardianship of Monuments, there is respect for human creativity that constitutes demonstration of humanity and demonstration of actions within the given culture related to a given social group. That culture cannot be ignored while establishing limits of legal protection of other goods protected by law, since it constitutes a basis for strengthening national identity. Despite the obligation of cooperation between public administration bodies in the course of the proceedings, to the extent necessary to clarify factual and legal state of the case, having regard to public interest and legitimate interest of the public, as well as efficiency of proceedings, by means of measures adequate to character, circumstances and complexity of the case (Art. 7a of the Code of Administrative Procedure), it is worth noticing the necessity for novelization of regulations pertaining to relationships of architec-

33 Rouba, B.J., Teoria w praktyce polskiej ochrony, konserwacji i restauracji dziedzictwa kultury. [in:] Szmygin, B. (ed.) Wspótczesne problemy teorii konserwatorskiej w Polsce. Wydawnictwo Politechniki Lubelskiej, Warszawa, Lublin, 2008, p. 102.

${ }^{34}$ See ibidem, p. 107. 
ture and construction administration bodies mentioned in Art. 28 of the Construction Law Act, in particular starosta and Provincial Heritage Conservation Officer, in such a way that in certain cases it is not necessary to issue two administrative decisions pertaining to one object, one of which is issued by Provincial Heritage Conservation Officer and another one by starosta. It would be necessary to ensure that, during a single proceeding, with cooperation of both interested bodies and party (parties), only one administrative decision is issued. The author believes that nowadays, during the proceedings before Provincial Heritage Conservation Officer aiming at obtaining a permit for construction works at a listed monument or in the surroundings thereof, competition of discussed values might be resolved by means of rules of conservation theory and administrative procedure mentioned in the Code of Administrative Procedure that allows to reach compromise, by means of mediation, between the scope of the right of a disabled person to live in a functionally accessible environment and the obligation to protect monuments.

Recibido: febrero de 2018. Aceptado: abril de 2018 


\section{BIBLIOGRAPHY}

\section{LEGAL DOCUMENTS}

1) Konwencja o prawach osób niepełnosprawnych sporządzona w Nowym Jorku dnia 13 grudnia 2006 r. (Dziennik Ustaw [Dz.U. - Journal of Laws] 2012, item 1169).

2) Konstytucja Rzeczypospolitej Polskiej z dnia 2 kwietnia 1997 r. (Dz. U. No. 78, item 483 with later amendments).

3) Powszechna Deklaracja Praw Człowieka przyjęta i proklamowana przez Zgromadzenie Ogólne Organizacji Narodów Zjednoczonych w dniu 10 grudnia 1948 roku.

4) Ustawa z dnia 14 czerwca $1960 \mathrm{r}$. Kodeks postępowania administracyjnego (consolidated text: Dz. U. 2013, item 267, with later amendments).

5) Ustawa z dnia 7 stycznia 1993 r. o planowaniu rodziny, ochronie płodu ludzkiego i warunkach dopuszczalności przerywania ciąży (Dz. U. No. 17, item 78, with later amendments).

6) Ustawa z dnia 27 sierpnia 1997 r. o rehabilitacji zawodowej i społecznej oraz zatrudnianiu osób niepełnosprawnych (consolidated text: Dz. U. 2016, item 2046, with later amendments).

7) Ustawa z dnia 23 lipca 2003 r. o ochronie zabytków i opiece nad zabytkami (Dz. U. No. 162, item 1568, with later amendments).

8) Ustawa z dnia 15 czerwca 2012 r. o ratyfikacji Konwencji o prawach osób niepełnosprawnych, sporządzonej w Nowym Jorku dnia 13 grudnia 2006 r. (Dz. U. item 882).

9) Rozporządzenie Ministra Pracy i Polityki Społecznej z dnia 27 listopada 2007 r. w sprawie turnusów rehabilitacyjnych (Dz. U. No. 230, item 1694, with later amendments).

10) Rozporządzenie Ministra Infrastruktury z dnia 12 kwietnia 2002 r. w sprawie warunków technicznych, jakim powinny odpowiadać budynki i ich usytuowanie (consolidated text: Dz. U. 2015, item 1422).

11) Karta praw osób niepełnosprawnych zatwierdzona uchwałą Sejmu Rzeczpospolitej z dnia 1 sierpnia 1997 r. (M.P. [Monitor Polski - Official Gazette of the Government of the Republic of Poland] No. 50, item 475).

\section{REFERENCES}

BARnés VÁzquez, J.. “El procedimiento administrativo y el gobierno electrónico”, http://repositorio.gobiernolocal.es/xmlui/bitstream/handle/10873/968/claves12_08_barnes.pdf?sequence $=1$ [06.11.2017].

BARnES, J., "Introduction reform and innovation in administrative procedure". http://en.globallawpress.org/wp-content/uploads/Book2IntroENG.pdf [01.11.2017].

Barnes, J. "Procedimientos administrativos de tercera generacion”, https://revistas-colaboracion. juridicas.unam.mx/index.php/opera-prima-derecho-admin/article/viewFile/1428/1329 [06.11.2017].

Barnes, J., “towards a third generation of administrative procedures," First draft -2016 Conference on Comparative Administrative Law April 29-30, 2016, https://law.yale.edu/ system/files/area/conference/compadmin/compadmin16_barnes_towards.pdf [01.11.2017]. 
Barnes, J., “Tres generaciones del procedimiento administrativo”, Derecho PUCP. Revista de la Facultad de Derecho No 67, 2011, http://revistas.pucp.edu.pe/index.php/derechopucp/article/ view/2992/3508 [05.11.2017].

ĆwıkııŃska, M., “Trzy generacje postępowania administracyjnego a Kodeks postępowania administracyjnego.” Acta Universitatis Lodziensis. Folia Iuridica 75, 2015.

DutKIEW ICZ, P., Problem aksjologicznych podstaw prawa we wspótczesnej polskiej filozofii i teorii prawa, Wydawnictwo Uniwersytetu Jagiellońskiego, Kraków.

Höfre, O., Etyka państwa i prawa. Wydawnictwo Znak, Kraków, 1992.

Jan Paweł II, Oredzie na światowy dzień pokoju, 1999. [Quoted from:] Rynio, A., Solidarność w nauczaniu Jana Pawta II. Wybór tekstów. Fundacja Servire Veritati Instytut Edukacji Narodowej, Lublin 2005.

KMieciak, Z., "Idea procedur administracyjnych trzeciej generacji (na przykładzie postępowania w sprawie dofinansowania projektów w ramach programów operacyjnych)", Państwo i Prawo 5/2015.

Kość, A., Podstawy filozofii prawa. "Petit," Lublin, 2001.

Krąpiec, M.A., Cztowiek i prawo naturalne. Dzieta X, Redakcja Wydawnictw KUL, Lublin, 1993.

ŁĄCzKowski, W., Granice prawa. [In:] Depo, W., Leszczyński, M., Guz, T., Marzec, P. (eds.), Veritatem in Caritate. Księga Jubileuszowa z okazji 70. urodzin Ksiedza Biskupa Profesora Jana Śrutwy. Wydawnictwo KUL, Lublin 2011.

Łączkowski, W., Ograniczenia prawa stanowionego. [In:] Dębiński, A., Pomorska, A., Smoleń, P. (eds.) W stużbie nauki prawa finansowego. Jubileusz obecności profesora Jana Gtuchowskiego w Katedrze Finansów i Prawa Finansowego Katolickiego Uniwersytetu Lubelskiego Jana Pawta II. Wydawnictwo KUL, Lublin 2010.

Łączkowski, W., Prawo a zmiana ustroju państwa. Wydawnictwo Naukowe Uniwersytetu Adama Mickiewicza, Poznań, 1992.

Ostrowska, M., Cztowiek a rzeczywistość przestrzenna. Oficyna Wydawnicza Nauka i Życie, Szczecin 1991.

RoubA, B.J., Teoria w praktyce polskiej ochrony, konserwacji i restauracji dziedzictwa kultury. [In:] Szmygin, B. (ed.) Wspótczesne problemy teorii konserwatorskiej w Polsce. Wydawnictwo Politechniki Lubelskiej, Warszawa, Lublin, 2008.

Sienkiewicz, T., Prawo cztowieka niepetnosprawnego do życia w środowisku uksztattowanym funkcjonalnie, Wydawnictwo Polihymnia, Lublin, 2004.

Sienkiewicz, T., Racjonalność decyzji administracyjnej. [In:] P. Marzec (ed.), Servire veritati. Księga jubileuszowa zokazji siedemdziesiatych urodzin Profesora Kazimierza A. Ktosińskiego. Wydawnictwo KUL, Lublin, 2011.

Sien KIEWICZ, T. Status cztowieka niepetnosprawnego w prawie administracyjnym. Krajowa Izba Gospodarczo-Rehabilitacyjna, Warszawa, 2006.

Sienkiewicz, T. Status cztowieka niepetnosprawnego w prawie publicznym. Krajowa Izba Gospodarczo-Rehabilitacyjna, Warszawa, 2007.

STYczeń, T., Wprowadzenie do etyki, TN KUL, Lublin, 1995.

Wiśniewski, L., Wolności i prawa osobiste w Konstytucji RP z 1997 roku i w prawie międzynarodowym, “Terra," Poznań, 1998. 
Ternon, Y., Helman, S., Eksterminacja chorych psychicznie w III Rzeszy. Od teoretyków narodowosocjalistycznych do praktyków z SS, Państwowy Zakład Wydawnictw Lekarskich, Warszawa, 1974.

ZDYB, M, "Państwo prawa w perspektywie zaszłości historycznych oraz dokonujących się zmian." [In:] Fundowicz, S., (ed.) Współczesne problemy prawa publicznego. Studia z prawa publicznego, vol. 1, Lublin, 1999.

ZDyв, M., Prawny interes jednostki $w$ sferze materialnego prawa administracyjnego. Studium teoretyczno-prawne. Wydawnictwo Uniwersytetu Marii Curie-Skłodowskiej, Lublin, 1991.

ZeIdler, K., O wtaściwy ksztatt stużby ochrony zabytków w Polsce. Postulaty de lege ferenda. [In:] Gardocka, T., Sobczak, J. (eds.), Prawna ochrona dóbr kultury. Wydawnictwo Adam Marszałek, Toruń, 2009.

Ziembiński, Z., Wstęp do aksjologii dla prawników. Wydawnictwo Prawnicze, Warszawa, 1990. 


\section{REVISORES}

María Dolores Adam Muñoz (Universidad de Córdoba)

Miguel Ángel Boldova Pasamar (Universidad de Zaragoza)

Antonio Cayón Galiardo (Universidad Complutense de Madrid)

María del Pilar Diago Diago (Universidad de Zaragoza)

María José Fernández Pavés (Universidad de Granada)

Gabriel García Cantero (Universidad de Zaragoza)

Pedro González de la Fe (Universidad de Las Palmas de Gran Canaria)

Andrés González Sanfiel (Universidad de La Laguna)

Ulises Hernández Plasencia (Universidad de La Laguna)

Mar Jimeno Bulnes (Universidad de Burgos)

Arantza Libano Beristain (Universidad Autónoma de Barcelona)

José Luis Linares Pineda (Universidad de Girona)

Cesare Maroli (Universitá di Bologna)

José María Miquel GonzÁlez (Universidad Autónoma de Madrid)

Cristóbal Molina Navarrete (Universidad de Jaén)

María del Carmen Núńez Lozano (Universidad de Huelva)

Javier Plaza Penadés (Universidad de Valencia)

Encarnación Ricart Martí (Universidad Rovira y Virgili de Tarragona)

Gloria Pilar Rojas Rivero (Universidad de La Laguna)

Dulce María Santana Vega (Universidad de Las Palmas de Gran Canaria)

Eloy Ruiloba García (Universidad de Málaga)

Gumersindo Ruiz Bravo de Mansilla (Universidad de Málaga)

Ambrosio Sampere Flores (Universidad de Murcia)

María Elena SÁnchez JoRdÁn (Universidad de La Laguna)

José Luis Sánchez-Parodi Pascua (Universidad de La Laguna)

Dulce María Santana Vega (Universidad de Las Palmas de Gran Canaria)

José María Souvirón Morenilla (Universidad de Málaga)

José Suay Rincón (Universidad de Las Palmas de Gran Canaria)

José Manuel Ventura Ventura (Universidad de La Rioja)

Francisco Villar Rojas (Universidad de La Laguna)

María Zambonino Pulito (Universidad de Cádiz) 

El equipo de dirección se reunió a finales del mes abril de 2019 para tomar decisiones sobre el proceso editorial del número 35 de AFDULL. El tiempo medio transcurrido entre recepción, evaluación, aceptación, edición y publicación final de los trabajos fue de cuatro meses.

Estadística:

Núm. de trabajos recibidos: 6 .

Núm. de trabajos aceptados para publicación: 3 (50\%).

Media de revisores por trabajo: 2 .

Media de tiempo entre envío y aceptación: 4 meses.

Media de tiempo entre aceptación y publicación: 12 meses.

Los revisores varían en cada número, en atención al tema de los trabajos presentados. 

(Adoptadas por el Consejo de Redacción en su sesión de 9 de abril de 2018; pendientes de ratificación por la Junta de la Facultad de Derecho)

Primera. La revista se publica en formato digital, en un número anual, con dos fascículos semestrales a través de la plataforma de gestión de revistas on line de la Universidad de La Laguna: http://revistas.webs.ull.es/index.php/derecho. Los trabajos que se presenten al proceso de selección para su publicación deberán cumplir las siguientes normas:

a) Plazo y forma de presentación. La revista tiene permanentemente abierta su convocatoria de propuestas de publicación. Las propuestas podrán ser sometidas a consideración por sus autores a través de la plataforma de gestión de revistas on line de la Universidad de La Laguna: http://revistas.webs.ull.es/index.php/derecho.

b) Autores. Solo podrán presentar trabajos en la revista aquellas personas que reúnan la cualidad de titulados en alguna de las enseñanzas universitarias oficiales de Grado, Máster y Doctorado, o categorías equivalentes. Los autores deberán identificar su categoría académica y/o profesional, así como cuál es la institución a la que pertenecen.

c) Temática. Los trabajos deben ser investigaciones de contenido jurídico.

Excepcionalmente y de manera subsidiaria podrán incluirse trabajos de materias afines si los miembros del Consejo de Redacción asistentes unánimemente así lo consideran.

d) Estructura y formato de los trabajos.

I. Para la sección Artículos: los trabajos no deben exceder de los 60000 caracteres con espacios (unas 20 páginas) y tendrán un título (en español e inglés), como mínimo tres palabras clave (en español e inglés) y un resumen (en español e inglés). No deberá incluirse ni sumario ni bibliografía final. Las propuestas de publicación se presentarán en archivo en formato editable: Word o rtf.

II. Para la sección Comentarios, de legislación y jurisprudencia: los trabajos no deben exceder de los 30000 caracteres con espacios (unas 10 páginas) y tendrán un título (en español e inglés), como mínimo tres palabras clave (en español e inglés) y un resumen (en español e inglés). No deberá incluirse ni sumario ni bibliografía final. Las propuestas de publicación se presentarán en archivo en formato editable: Word o rtf.

III. El formato del texto principal será Times New Roman, a espacio y medio, tamaño de letra 12; y para las notas a pie de página es Times New Roman, a un espacio y con tamańo de letra 10. Las normas para las citas son las siguientes: A) Artículos de revistas. Ejemplo: SAAvedra Ruiz, J., «La iniciativa del tribunal en el acto del juicio oral», Cuadernos de Derecho Judicial, n. ${ }^{\circ} 10,1994$, p. 13 y ss. B) Libros/monografías. Ejemplo: Ortells Ramos, M., El proceso penalabreviado, Comares, Granada, 1997.

e) Idioma. Los trabajos deberán estar escritos en lengua española, o en alguna lengua extranjera de relevancia en el ámbito jurídico siempre que la revista cuente con revisores que conozcan la lengua extranjera y sean expertos en el área de conocimiento de la propuesta presentada. En todo caso, el título, las palabras clave y el abstract deberán presentarse en espańol e inglés. 
f) Originalidad de los trabajos. Todos deben ser inéditos y no deben estar pendientes de publicación en otra revista o libro.

Segunda. La presentación de un trabajo en la revista Anales de la Facultad de Derecho de la Universidad de La Laguna conlleva el conocimiento y la aceptación de las siguientes normas por parte de los autores:

1. Es condición para la publicación que el autor o autores ceda(n) a la revista, en exclusiva, los derechos de reproducción, así como que consientan su inclusión en bases de datos, catálogos, bibliotecas, índices o servidores que permitan la mayor difusión de las investigaciones. Si se producen peticiones de terceros para reproducir o traducir artículos o partes de los mismos, la decisión corresponderá al Consejo de Redacción.

2. De las opiniones sustentadas en los trabajos firmados responden exclusivamente sus autores. La publicación de los diferentes artículos no implica adhesión ni conformidad de la revista con las opiniones mantenidas por los autores.

Tercera. Se asignará uno o dos evaluadores, preferiblemente externos, por cada uno de los originales presentados, según la materia sobre la que versen los mismos, para que informen en el plazo que se establezca sobre la conveniencia de su publicación. La evaluación será anónima en todo momento, de manera que los autores no conocerán quién evaluó su trabajo ni el evaluador conocerá quién es el autor.

Cuarta. Pese a ser la evaluación anónima, en el caso de concurrir causa de abstención en alguno de los miembros propuestos o cuando este lo proponga de manera motivada, se podrá designar a otro/s evaluador/es experto/s en la materia que se evalúa.

Quinta. Cada evaluador rendirá su informe teniendo en cuenta los siguientes criterios: la calidad y rigor de los argumentos presentados; la oportunidad y relevancia del artículo; la creatividad, metodología, propuestas y aportaciones; así como la adecuación a las normas de publicación. Los informes tendrán carácter confidencial y reservado.

SeXta. Una vez transcurrido el plazo para presentar los informes de evaluación, se reunirá el Consejo de Redacción, al que se dará cuenta del punto en el que se encuentra el proceso, llevándose a cabo la valoración del resultado de las evaluaciones. Cuando exista contradicción entre los informes emitidos, el Consejo de Redacción designará a un tercer experto en la materia, para que proceda a una nueva evaluación.

SÉptima. Se trasladará al autor el resultado de la evaluación y, en su caso, las modificaciones sugeridas por los expertos, con la advertencia de que el Consejo de Redacción se reserva el derecho a no publicar el original presentado cuando no se observaren las modificaciones propuestas por los expertos.

Octava. Cuando algún miembro del Consejo de Redacción fuere autor del original presentado deberá ausentarse de las votaciones. 


\section{Servicio de Publicaciones \\ Universidad de La Laguna}

